\title{
Expert Consensus for Multi-Modality Imaging Evaluation of Cardiovascular Complications of Radiotherapy in Adults: A Report from the European Association of Cardiovascular Imaging and the American Society of Echocardiography
}

\begin{abstract}
Patrizio Lancellotti, ${ }^{*}$ Vuyisile T. Nkomo, Luigi P. Badano, Jutta Bergler, Jan Bogaert, Laurent Davin, Bernard Cosyns, Philippe Coucke, Raluca Dulgheru, Thor Edvardsen, Oliver Gaemperli, Maurizio Galderisi, Brian Griffin, Paul A. Heidenreich, Koen Nieman, Juan C. Plana, Steven C. Port, Marielle Scherrer-Crosbie, Ronald G. Schwartz, Igal A. Sebag, Jens-Uwe Voigt, Samuel Wann, and Phillip C. Yang, In collaboration with the European Society of Cardiology Working Groups on Nuclear Cardiology and Cardiac Computed Tomography and Cardiovascular Magnetic Resonance and the American Society of Nuclear Cardiology, Society for Cardiovascular Magnetic Resonance, and Society of Cardiovascular Computed Tomography, Liegge, Brussels, Leuven, Belgium, Rochester, MN, Padua, Italy, Vienna, Austria, Bucharest, Romania, Oslo, Norway, Zurich, Switzerland, Naples, Italy, Cleveland, OH, Palo Alto, Stanford, CA, Rotterdam, The Netherlands, Milwankee, WI, Boston, MA, Rochester, NY, Montreal, Quebec, Canada
\end{abstract}

\begin{abstract}
Cardiac toxicity is one of the most concerning side effects of anti-cancer therapy. The gain in life expectancy obtained with anti-cancer therapy can be compromised by increased morbidity and mortality associated with its cardiac complications. While radiosensitivity of the heart was initially recognized only in the early 1970 s, the heart is regarded in the current era as one of the most critical dose-limiting organs in radiotherapy. Several clinical studies have identified adverse clinical consequences of radiation-induced heart disease (RIHD) on the outcome of long-term cancer survivors. A comprehensive review of potential cardiac complications related to radiotherapy is warranted. An evidence-based review of several imaging approaches used to detect, evaluate, and monitor RIHD is discussed. Recommendations for the early identification and monitoring of cardiovascular complications of radiotherapy by cardiac imaging are also proposed. (J Am Soc Echocardiogr 2013;26:1013-32.)
\end{abstract}

Keywords: Radiotherapy, Echocardiography, Cardiac magnetic resonance, Nuclear cardiology, Cardiac computed tomography, Heart disease

From the Department of Cardiology, GIGA Cardiovascular Sciences, Heart Valve Clinic, University of Liège Hospital, CHU du Sart-Tilman, Liège 4000, Belgium (P.L.); Division of Cardiovascular Diseases and Internal Medicine, Mayo Clinic, Rochester, MN (V.T.N.); Department of Cardiac, Vascular and Thoracic Sciences, University of Padua, Padua, Italy (L.P.B.); Department of Cardiology, Medical University of Vienna, Vienna, Austria (J. Bergler); Department of Radiology, University Hospital Gasthuisberg, Catholic University of Leuven, Leuven, Belgium (J. Bogaert); Department of Cardiovascular Imaging and Invasive Cardiology, CHU du Sart-Tilman, Liège, Belgium (L.D.); Department of Cardiology, Centrum Voor Hart- en Vaatziekten (CHVZ), UZ Brussel, Laarbeeklaan 101, Brussels B-1090, Belgium (B.C.); Department of Radiotherapy, University Hospital, $\mathrm{CHU}$ de Liège, Liège, Belgium (P.C.); Department of Cardiology, Emergency University Hospital, University of Medicine and Pharmacy 'Carol Davila', Bucharest, Romania (R.D.); Department of Cardiology, Oslo University Hospital, Rikshospitalet, Oslo, Norway (T.E.); Interventional Cardiology and Cardiac Imaging, Cardiovascular Center, University Hospital Zurich, Zurich, Switzerland (O.G.); Department of Clinical and Experimental Medicine, Cardioangiology with CCU, Federico II University Hospital, Naples, Italy (M.G.); Section of Cardiovascular Imaging, Department of Cardiovascular Medicine, Cleveland Clinic, Cleveland, OH (B.G., J.C.P.); VA Palo Alto Health Care System, Palo Alto, CA (P.A.H.); Department of Medicine, Stanford University, Stanford, CA (P.A.H.); Department of Cardiology, Erasmus University Medical Center, Rotterdam, The Netherlands (K.N.); Department of Radiology, Erasmus University Medical Center, Rotterdam, The Netherlands (K.N.); Aurora Cardiovascular Services, Aurora Health Care, Milwaukee, W
(S.C.P.); Cardiac Ultrasound Laboratory, Massachusetts General Hospital, Boston, MA (M.S.-C.); Department of Medicine, Division of Cardiology, University of Rochester Medical Center, Rochester, NY (R.G.S.); Department of Imaging Sciences, Division of Nuclear Medicine, University of Rochester Medical Center, Rochester, NY (R.G.S.); Division of Cardiology, Department of Medicine, Sir Mortimer B. Davis-Jewish General Hospital, Montreal, Quebec, Canada (I.A.S.) Lady Davis Institute for Medical Research, McGill University, Montreal, Quebec, Canada (I.A.S.); Department of Cardiovascular Diseases, University Hospital Gasthuisberg, Catholic University of Leuven, Leuven, Belgium (J.-U.V.); Heart Failure Program, Columbia St. Mary's Healthcare Milwaukee, WI (S.W.); and the Stanford University School of Medicine, Stanford, CA (P.C.Y.).

Conflict of interest: None declared.

Funding: No financial assistance was received to support this study.

Reprint requests: Tel: +32 4366 71 94; Fax: +32 43667195 (E-mail: plancellotti@ chu.ulg.ac.be).

0894-7317/\$36.00

Co-published in the European Heart Journal-Cardiovascular Imaging and Journal of the American Society of Echocardiography. Copyright $\odot 2013$ by The Authors; published by the American Society of Echocardiography with permission of the European Association of Cardiovascular Imaging of the European Society of Cardiology. For permissions please email: http://www.elsevier.com/authors/ obtaining-permission-to-re-use-elsevier-material

http://dx.doi.org/10.1016/j.echo.2013.07.005 


\section{TABLE OF CONTENTS}

Introduction 1015

Radiation Effects on the Heart 1015

Prevalence 1015

Population Risk Factors 1015

Pathophysiology 1015

Acute and Chronic Cardiovascular Toxicity 1016

Role of Imaging in Assessing 'RIHD' 1016

Specific Technical Considerations 1016

Imaging Findings 1019

Recommendations for Clinical Applications 1026

Screening and Comprehensive Follow-up Evaluation

Practical Use of Imaging Studies for Follow-up Evaluation

Conclusion and Future Directions 1030

Notice and Disclaimer 1030

References 1030

\section{INTRODUCTION}

The two major contributors to radiation exposure in the population are ubiquitous background radiation and medical exposure. ${ }^{1}$ A high-dose radiation exposure on the thorax is mainly used in the context of adjuvant radiotherapy after conservative or radical breast surgery, adjuvant or exclusive radiotherapy of lung and oesophageal cancer, and as a complement to systemic treatment in lymphoma. Irradiation of the heart increases the risk of the so-called 'radiation-induced' heart disease (RIHD) ${ }^{2}$ RIHD is generated by total cumulative dosage of radiotherapy potentiated by the adjunctive chemotherapy. The total cumulative dosage of radiotherapy is a function of the number of treatments and the dose of irradiation. ${ }^{3}$ The manifestations of RIHD may acutely develop but most often become clinically apparent several years after irradiation. RIHD holds a wide range of deleterious effects on the heart including pericarditis, coronary artery disease (CAD), myocardial infarction, valvular heart disease, rhythm abnormalities, and non-ischaemic myocardial and conduction system damages. The number of patients at risk of developing RIHD is likely to increase as $\sim 40 \%$ of cancer survivors are at least 10 years past their radiotherapy treatment. ${ }^{4}$ The development of RIHD may be accelerated by the contribution of shared common risk factors of cardiovascular disease and cancer such as obesity, inactivity, and substance abuse (i.e. tobacco and alcohol). Several clinical trials and epidemiologic studies have revealed the adverse impact of RIHD on the outcome of long-term cancer survivors. ${ }^{2,3}$ Appropriate recognition of potential cardiac complications related to radiotherapy is warranted in our day-to-day clinical practice. Several imaging approaches can be used to detect, evaluate, and monitor RIHD. This document represents a consensus summary by experts of an extensive review of the literature regarding the role of cardiac imaging in the detection and serial monitoring of RIHD.

\section{RADIATION EFFECTS ON THE HEART}

\section{Prevalence}

Evidence of the dose-dependent increase in cardiovascular disease after chest radiotherapy has been documented in several studies, especially in the field of breast cancer and lymphoma (Table 1). ${ }^{5-15}$ The estimated aggregate incidence of RIHD is $10-30 \%$ by $5-10$ years
Table 1 Relative risks of RIHD in cancer survivors

\begin{tabular}{lcc}
\multicolumn{1}{c}{ Types } & $\begin{array}{c}\text { Hodgkin's } \\
\text { disease relative risk }\end{array}$ & $\begin{array}{c}\text { Breast cancer } \\
\text { relative risk }\end{array}$ \\
\hline RIHD & $>6.3$ & $2-5.9$ \\
Ischaemic heart disease & $4.2-6.7$ & $1-2.3$ \\
Cardiac death & $2.2-12.7$ & $0.9-2$ \\
\hline
\end{tabular}

The reported relative risk of RIHD is proportional to radiation dose and time to exposure.

post-treatment. ${ }^{9}$ Among these patients who have received radiation, cardiovascular disease is the most common non-malignant cause of death. Comparing the long-term benefits and risks, the positive effect of adjuvant radiotherapy may thus be partially offset by cardiac complications. However, the precise prevalence of RIHD is difficult to determine because currently available data mainly come from single-centre studies, often retrospective, in which old radiotherapy techniques were used, patients with a prior history of CAD were excluded, and baseline pre-radiotherapy imaging was lacking. The prevalence of RIHD in the setting of modern protocols of delivering adjuvant radiotherapy, reduction in doses, and field radiation size is still poorly defined.

\section{Population Risk Factors}

Despite considerable uncertainty, we are increasing our understanding of the factors that may influence the long-term risk of RIHD (Table 2). However, risk factors modulating the acute effects of cardiac radiation are hardly known. ${ }^{3}$ It appears that the cumulative dose and its fractioning determine acute and chronic cardiac effects of radiation therapy. In the past, pericarditis used to be the most common side effect in patients receiving traditional radiotherapy for Hodgkin's disease. ${ }^{9}$ Dose restriction to $30 \mathrm{~Gy}$ with lower daily fraction, different weighting of radiation fields, and blocking of the sub-carinal region have been reported to reduce the incidence of pericarditis from 20 to $2.5 \%$. While, in doses $>30$ Gy, the risk of RIHD becomes apparent, the nature and magnitude of lower doses is not well characterized nor is it clear whether there is a threshold dose below which there is no risk. ${ }^{3,7}$ Radiation increases the risk of cardiotoxic effects of certain chemotherapeutic agents, such as anthracyclines. ${ }^{13}$ This interaction appears to be dependent on the total cumulative dose of anthracyclines. ${ }^{14}$ Other patients and disease-related factors may potentially influence cardiac risk after ionizing radiation. Age at irradiation for breast cancer has been shown to influence the risk; patients younger than 35 have a relative risk of 6.5 than the general population of RIHD. ${ }^{15}$ Similar observations have been made in the case of Hodgkin's lymphoma. ${ }^{2,7}$ Smoking also increases the relative risk. Other risk factors such as diabetes, hypertension, overweight, and hypercholesterolaemia influence the overall risk. ${ }^{16}$ However, in some studies, no increase in cardiac risk, especially of myocardial infarction, has been observed after adjusting for preexisting cardiovascular risk factors. ${ }^{17}$

\section{Pathophysiology}

It is known that irradiation of a thoracic region encompassing the heart might be at the origin of acute and chronic RIHD. ${ }^{1}$ Current knowledge about acute radiation effects mainly derives from animal experiments, which do not necessarily reflect contemporary radiotherapy treatment strategies, neither in dosage nor in timing of irradiation. ${ }^{17}$ Furthermore, the processes from the acute injury to progressive 
Table 2 Risk factors of radiation-induced heart disease

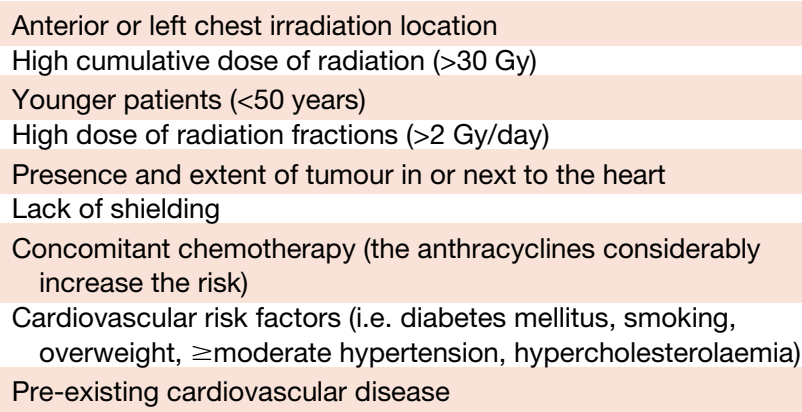

High-risk patients definition: anterior or left-side chest irradiation with $\geq 1$ risk factors for RIHD.

cardiac disease and the relationship between short-term effects and long-term risks in each individual patient are still subject to investigations and not fully understood. ${ }^{3}$ Ionizing radiation might harm virtually all cardiac tissues and the underlying pathophysiological mechanisms may be related to micro- and macrovascular damages. ${ }^{6,18}$ Early events in the post-radiation cascade are loss of endothelial cells with subsequent inflammatory responses, driving the vascular damage. ${ }^{19}$ Microvascular damage (decrease in capillary density resulting in ischaemia) is associated with eventual fibrosis and diastolic dysfunction and heart failure. Primary radiation fibrosis is not related to the primary effect of radiation, but rather to a reparative response of the heart tissue to injury in the microvascular system (Figure 1). ${ }^{5}$ This is a common pathological feature of late radiation tissue complications. ${ }^{20}$ Macrovascular damage includes accelerated atherosclerosis yielding endothelial dysfunction and coronary artery stenosis. ${ }^{3,21}$ The pathogenesis of this radiation-induced CAD shares common pathways with CAD driven by genetic and exogenous factors. ${ }^{5}$ As exogenous factors have been shown to result in genomic instability, and as low-dose radiation induces long-lasting genomic instability, a synergistic interaction between radiation-induced effects and pathogenic events unrelated to radiation exposure is highly probable.

\section{Acute and Chronic Cardiovascular Toxicity}

The clinical translations of the above radiation-induced pathophysiological changes are pericarditis, valvular heart disease, myocardial damage, microvascular dysfunction, CAD, myocardial ischaemia, and restrictive cardiomyopathy. These clinical entities differ with regard to latency, radiation exposure pattern, and clinical presentation. ${ }^{6,17,20}$ Acute radiation effects are commonly subtle, difficult to assess in patients, and clinically less relevant. Acute radiation effects must be suspected and investigated in patients with cardiovascular complaints early after radiotherapy. The late manifestations of RIHD usually become clinically overt several years after radiation. The symptoms and signs of RIHD are, for the most part, indistinguishable from those encountered in patients with heart disease due to other aetiologies. Table 3 gives a summary of the pathophysiological manifestations of RIHD for different radiosensitive structures within the heart.

\section{ROLE OF IMAGING IN ASSESSING 'RIHD’}

In oncological patients, cardiac imaging is classically dictated either by the symptomatic status or by the presence of suggestive physical ex- amination findings. Echocardiography takes a central role in evaluating the morphology and function of the heart and represents the first imaging modality in the majority of cases. Other imaging modalities, including cardiac computed tomography (CT), cardiac magnetic resonance (CMR), and nuclear cardiology, are used to confirm and evaluate the extent of RIHD. Although their use is often complementary, their clinical utility depends on the type of pathological features. For instance, the role of nuclear cardiology for assessing pericardial structures, myocardial fibrosis, or valvular heart disease associated with RIHD is limited by its suboptimal spatial resolution. Conversely, the sensitivity of cardiac CT to detect localized pericardial effusion and pericardial thickening and the accuracy of CMR in characterization of myocardial oedema, inflammation, and fibrosis are superior to echocardiography.

\section{Specific Technical Considerations}

Echocardiography. Detection of any cardiac structure abnormality, measurement of left ventricular (LV) performance, and evaluation of valvular disease severity are critical components of the assessment and management of RIHD. ${ }^{22}$ Several echocardiographic approaches (M-mode, Doppler, two-/three-dimensional (2D/3D) transthoracic or transoesophageal, contrast, or stress echocardiography) can be used according to the clinical indications. Unless $3 \mathrm{D}$ echocardiography is used, the 2D biplane disk summation method (biplane Simspon's) is recommended for the estimation of $\mathrm{LV}$ volumes and ejection fraction. Contrary to 2D, 3D echocardiography makes no assumptions about the LV shape and avoids foreshortened views resulting in a better accuracy regarding the assessment of LV mass and volumes. ${ }^{23} \mathrm{~A} \mathrm{com}-$ mon limitation of $2 \mathrm{D} / 3 \mathrm{D}$ is the suboptimal visualization of the endocardial border. This happens particularly in patients with obesity, respiratory disease, thoracic deformity, or previous open-chest cardiac surgery. When more than two segments are not adequately visualized, the use of contrast agents for endocardial border definition improves inter-observer variability to a level comparable with CMR. ${ }^{24} \mathrm{New}$ currently available techniques (tissue Doppler imaging and 2D speckle tracking) may yield complementary information for the assessment of LV function. ${ }^{25}$ Although tissue Doppler-derived velocity parameters are easier to obtain, deformation imaging (strain and strain rate) appears more sensitive to detect subtle function changes and may become a valuable clinical tool to assess myocardial function in oncology patients. $^{26,27} 2 \mathrm{D}$ speckle tracking echocardiography is an accurate angle-independent modality for the quantification of strain, a measure of LV systolic function, while tissue Doppler imaging is angle dependent and its derived velocities are widely affected by tethering to adjacent segments and the overall motion of the heart. Due to its high degree of automation, 2D speckle tracking is particularly suited for repetitive follow-up examinations by different echocardiographers. ${ }^{25}$ The main drawback of the 2D speckle tracking approach is that the results are affected by the image quality. Further, to guarantee comparability, serial studies should be performed on the same platform and software release. For valve analysis, transthoracic Doppler echocardiography is the recommended first-line imaging, whereas transoesophageal echocardiography is advocated in the absence of contraindications when transthoracic echocardiography is nondiagnostic or when further diagnostic refinement is required. 3D echocardiography is reasonable to provide additional information in patients with complex valve lesions.

Cardiac Magnetic Resonance. CMR physics and image acquisition strategies are discussed elsewhere. ${ }^{28}$ Black-blood $T_{1}$-weighted 


\section{CHEST RADIATION EXPOSURE}

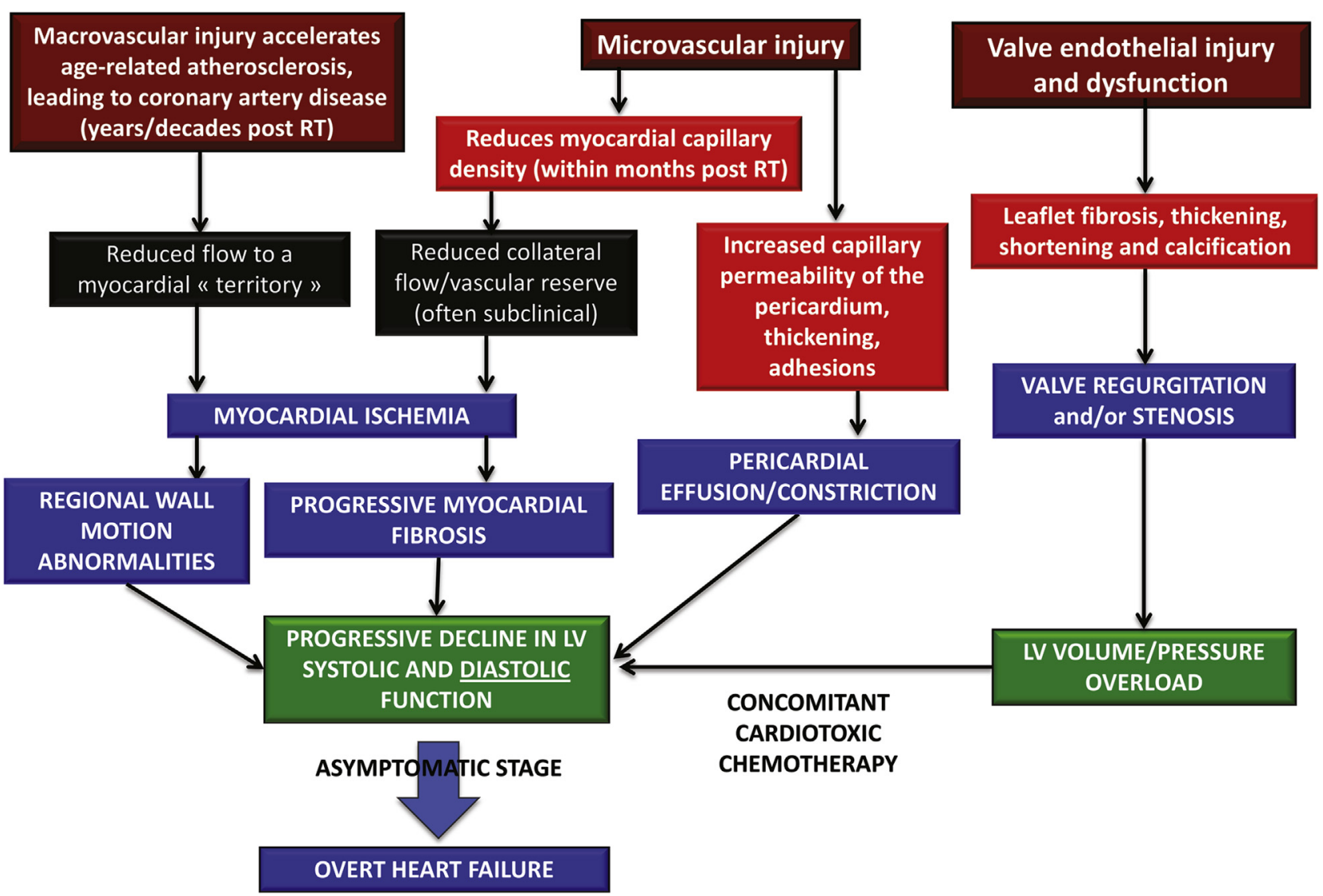

Figure 1 Pathophysiological manifestations of radiation-induced heart disease for different radiosensitive structures within the heart. $L V$, Left ventricle; $R T$, radiotherapy.

fast spin-echo CMR provides an excellent morphologic view of the heart, pericardium, great vessels, and adjacent structures. $T_{2}$-weighted fast spin-echo imaging, using a short-tau inversion-recovery (STIR) sequence (triple inversion-recovery), depicts increased free water as areas of high signal intensity. ${ }^{29}$ This sequence allows the visualization of myocardial oedema in the setting of acute myocarditis, or pericardial oedema in patients with inflammatory pericarditis. ${ }^{30}$ More quantitative data can be obtained using $T_{2}$-mapping techniques. ${ }^{31}$ Gadolinium-based paramagnetic contrast agents are routinely used in clinical CMR. Following intravenous injection, the first pass of contrast agent can be used for single-phase or time-resolved 3D MR angiography, and for myocardial perfusion imaging. The latter can be performed during infusion of a vasodilator (e.g. adenosine and dipyridamole) to visualize LV segmental perfusion abnormalities due to haemodynamically significant coronary artery stenosis. Normal myocardium is typically characterized by a rapid wash-in and wash-out Conversely, in an abnormal myocardium, such as necrotic or fibrotic myocardium, the concentration of gadolinium increases over time owing to an increased extracellular volume distribution with de creased wash-out. These regions are typically hyper-intense (i.e. bright). With the advent of the inversion-recovery-based CMR sequences, the so-called late-/delayed- (gadolinium) enhancement (LGE) imaging technique, irreversible myocardial damage as small as $1 \mathrm{~g}$, can be depicted. ${ }^{32}$ The pattern, location, and extent of myocardial enhancement enable the differentiation of ischaemic from non- ischaemic causes. ${ }^{33}$ To depict diffuse myocardial fibrosis, $T_{1}$-mapping techniques have been recently proposed. These calculate the postcontrast $T_{1}$ relaxation time. ${ }^{34,35}$ Bright-blood cine CMR imaging, using balanced steady-state free precession (SSFP) gradient-echo sequences, provides dynamic information to quantify ventricular volumes, function, and mass, to assess regional myocardial function, and to visualize valvular heart disease. ${ }^{36}$ In addition, myocardial deformation patterns can be assessed by CMR tagging techniques. ${ }^{37} \mathrm{~A}$ final, important CMR technique is velocity-encoded or phase-contrast cine $\mathrm{CMR}^{38}$ This sequence measures the degree of 'dephasing' caused by through-plane motion of protons. This versatile sequence can be used to measure flow velocities (and volumes) in blood vessels, to calculate severity of shunts, to quantify velocities and regurgitation through valves, and to possibly assess diastolic function. The main limitation of CMR is that it is impractical in patients with pacemakers, claustrophobia, and anxiety attacks, and may present some difficulties in children and very obese patients. Moreover, the inability to carry out repeated breath holds and the presence of arrhythmias might represent additional problems. Finally, CMR may not be available in some community hospitals and access to CMR is limited in some in stitutions.

Cardiac CT. Cardiac CT offers detailed cross-sectional anatomical imaging of the chest. Intravenous injection of contrast medium opacifies the cardiac cavities and vessels and allows differentiation 
Table 3 Radiation effects on the heart

\begin{tabular}{|c|c|}
\hline Acute & Long-term \\
\hline $\begin{array}{l}\text { Pericarditis } \\
\text { - Acute exudative pericarditis is rare and often occurs during } \\
\text { radiotherapy as a reaction to necrosis/inflammation of a tumour } \\
\text { located next to the heart. }\end{array}$ & $\begin{array}{l}\text { Pericarditis } \\
\text { - Delayed chronic pericarditis appears several weeks to years } \\
\text { after radiotherapy. In this type, extensive fibrous thickening, } \\
\text { adhesions, chronic constriction, and chronic pericardial } \\
\text { effusion can be observed. It is observed in up to } 20 \% \text { of } \\
\text { patients within } 2 \text { years following irradiation. }\end{array}$ \\
\hline $\begin{array}{l}\text { Delayed acute pericarditis occurs within weeks after radiotherapy } \\
\text { and can be revealed by either an asymptomatic pericardial } \\
\text { effusion or a symptomatic pericarditis. Cardiac tamponade is rare. } \\
\text { Spontaneous clearance of this effusion may take up to } 2 \text { years. }\end{array}$ & $\begin{array}{l}\text { - Constrictive pericarditis can be observed in } 4-20 \% \text { of patients } \\
\text { and appears to be dose-dependent and related to the } \\
\text { presence of pericardial effusion in the delayed acute phase. }\end{array}$ \\
\hline Cardiomyopathy & Cardiomyopathy \\
\hline \multirow[t]{2}{*}{$\begin{array}{l}\text { - Acute myocarditis related to radiation-induced inflammation with } \\
\text { transient repolarization abnormalities and mild myocardial } \\
\text { dysfunction. }\end{array}$} & $\begin{array}{l}\text { - Diffuse myocardial fibrosis (often after a }>30-\text { Gy radiation dose) } \\
\text { with relevant systolic and diastolic dysfunction, conduction } \\
\text { disturbance, and autonomic dysfunction. }\end{array}$ \\
\hline & $\begin{array}{l}\text { - Restrictive cardiomyopathy represents an advanced stage of } \\
\text { myocardial damage due to fibrosis with severe diastolic } \\
\text { dysfunction and signs and symptoms of heart failure }\end{array}$ \\
\hline Valve disease & Valve disease \\
\hline \multirow[t]{4}{*}{ - No immediate apparent effects. } & $\begin{array}{l}\text { - Valve apparatus and leaflet thickening, fibrosis, shortening, and } \\
\text { calcification predominant on left-sided valves (related to } \\
\text { pressure difference between the left and right side of the heart). }\end{array}$ \\
\hline & $\begin{array}{l}\text { - Valve regurgitation more commonly encountered than stenosis. } \\
\text { - Stenotic lesions more commonly involving the aortic valve. }\end{array}$ \\
\hline & $\begin{array}{l}\text { - Reported incidence of clinically significant valve disease: } 1 \% \text { at } \\
10 \text { years; } 5 \% \text { at } 15 \text { years; } 6 \% \text { at } 20 \text { years after radiation } \\
\text { exposure. }\end{array}$ \\
\hline & $\begin{array}{l}\text { - Valve disease incidence increases significantly after }>20 \text { years } \\
\text { following irradiation: mild AR up to } 45 \%, \geq \text { moderate AR up to } \\
15 \%, \text { AS up to } 16 \% \text {, mild MR up to } 48 \% \text {, mild PR up to } 12 \% \text {. }\end{array}$ \\
\hline \multirow{3}{*}{$\begin{array}{l}\text { Coronary artery disease } \\
\text { - No immediate apparent effects. (Perfusion defects can be seen in } \\
47 \% \text { of patients } 6 \text { months after radiotherapy and may be } \\
\text { accompanied by wall-motion abnormalities and chest pain. Their } \\
\text { long-term prognosis and significance are unknown.) }\end{array}$} & Coronary artery disease \\
\hline & $\begin{array}{l}\text { - Accelerated CAD appearing in the young age. } \\
\text { - Concomitant atherosclerotic risk factors further enhance the } \\
\text { development of CAD. } \\
\text { - Latent until at least } 10 \text { years after exposure. (Patients younger } \\
\text { than } 50 \text { years tend to develop CAD in the first decade after } \\
\text { treatment, while older patients have longer latency periods.) }\end{array}$ \\
\hline & $\begin{array}{l}\text { - Coronary ostia and proximal segments are typically involved. } \\
\text { - CAD doubles the risk of death; relative risk of death from fatal } \\
\text { myocardial infarction varies from } 2.2 \text { to } 8.8 \text {. }\end{array}$ \\
\hline Carotid artery disease & Carotid artery disease \\
\hline \multirow[t]{2}{*}{ - No immediate apparent effects. } & $\begin{array}{l}\text { - Radiotherapy-induced lesions are more extensive, involving } \\
\text { longer segments and atypical areas of carotid segments. }\end{array}$ \\
\hline & $\begin{array}{l}\text { - Estimated incidence (including sub-clavian artery stenosis) } \\
\text { about } 7.4 \% \text { in Hodgkin's lymphoma. }\end{array}$ \\
\hline Other vascular disease & Other vascular disease \\
\hline \multirow[t]{2}{*}{ - No immediate apparent effects. } & $\begin{array}{l}\text { - Calcification of the ascending aorta and aortic arch (porcelain } \\
\text { aorta). }\end{array}$ \\
\hline & $\begin{array}{l}\text { - Lesions of any other vascular segments present within the } \\
\text { radiation field. }\end{array}$ \\
\hline
\end{tabular}

$A R$, Aortic regurgitation; $A S$, aortic stenosis; $C A D$, coronary artery disease; $M R$, mitral regurgitation; $P R$, pulmonary regurgitation.

from the surrounding tissues. ${ }^{39}$ By synchronizing the acquisition or reconstruction of images to the electrocardiogram (ECG), motion-free, and phase-consistent images of the heart can be obtained, which is important for robust depiction of the coronary arteries and functional analyses. Advantages of cardiac CT in comparison with other imaging modalities include high-spatial resolution, short-exam times, and high sensitivity for calcified tissues. CT is the only non-invasive technique that can reliably image the coronary arteries. Drawbacks are the need for iodine-containing contrast media, ionizing radiation, breath holding, lower heart rates, and the inter-machine variation in radiation dose. Contemporary CT systems are equipped with 64 or more detector rows, which allow imaging of the entire heart in five heart 
cycles or fewer. ECG synchronization is accomplished by retrograde ECG gating for spiral scanning, or prospective ECG triggering for axial scan modes. By limiting exposure to the phase of interest (generally, the motion sparse diastolic phase), the radiation dose can be reduced. Contemporary scanner technology and scan protocols for coronary imaging are associated with an average radiation dose of $<5 \mathrm{mSv}{ }^{39}$ Cardiac CT examinations that include full-cycle exposure are associated with a higher radiation dose, which represents a significant limitation, especially if follow-up is the goal of the examination.

Nuclear Cardiology. Cardiac radionuclide imaging (single-photon emission CT, SPECT and positron emission tomography, PET) encompasses a variety of techniques designed to provide valuable information in detecting the presence and extent of cardiac disease. ${ }^{40}$ Two radioisotopes are routinely used in SPECT perfusion imaging: ${ }^{201} \mathrm{Tl}$ and ${ }^{99 \mathrm{~m}} \mathrm{Tc}$ (bound to either sestamibi or tetrofosmin). Imaging can be performed at rest and during stress (exercise or pharmacological), which allows the determination of regional perfusion defects (ischaemia or infarction/scar). ECG-gated SPECT ventriculography by either myocardial perfusion or by blood pool techniques provides highly accurate, reproducible, and prognostically validated measurements of LV end-systolic volume, end-diastolic volume, and ejection fraction. Technetium-based tracers are preferred over thallium for gated acquisitions due to the higher count statistics. Limitations of the techniques relate to its radiation exposure, ability to reproduce the same position on initial and delayed (or rest) images, and the need to select the longest cardiac cycles during ECG-gated imaging to optimize the assessment of LV ejection fraction and volume indices in cases of unstable rhythm. Radiation exposure depends on the radionuclide agents, ranging between 3 and $22 \mathrm{mSv}$, but with current cadmium zinc telluride (CZT) SPECT technology these exposures can be readily reduced to the $<12 \mathrm{mSv}$ range. ${ }^{41}$ PET myocardial perfusion with ${ }^{13} \mathrm{NH}_{4}$ or ${ }^{82} \mathrm{Ru}$ has attractive features as a screening tool in survivors of mediastinal irradiation. ${ }^{42}$ Its intrinsic higher resolution, higher count rate, and more robust attenuation correction allow for accurate quantification of myocardial blood flow. However, the availability of PET is more restricted, because the majority of PET tracers (except for ${ }^{82} \mathrm{Ru}$ ) require an onsite cyclotron.

Of note, the current generation of new CZT SPECT gamma cameras provide superior spatial resolution compared with traditional sodium iodide SPECT systems (spatial resolution 8-10 $\mathrm{mm}$ ) and approach effective spatial resolution of PET (spatial resolution 4-5 $\mathrm{mm}$ ) cameras. $^{43}$ ECG-gated myocardial perfusion SPECT imaging and equilibrium-gated radionuclide angiocardiography (ERNA) provide an quantitative assessment of LV volume indices, ejection fraction, and diastolic peak filling rate, which are all of proven value for risk stratification in patients with ischaemic, valvular, and myocardial diseases. In valvular heart disease, the inability to assess valve morphology and its severity limits the use of these techniques. Moreover, these techniques have not yet been tested in patients with known or suspected RIHD.

\section{Imaging Findings}

Pericarditis. In radiation-induced pericarditis, heart imaging is useful for evaluating the degree of pericardial thickening, the extent of pericardial calcification, the presence of constrictive physiology, the presence and quantification of a pericardial effusion, and for patient follow-up.

Echocardiography.-Pericardial thickening appears as increased echogenicity of the pericardium on 2D echocardiography and as mul- tiple parallel reflections posterior to the LV on M-mode recordings. ${ }^{43}$ However, the distinction between the normal and thickened pericardium may be difficult. Pericardial effusion is visualized as an echo-free space, external to the myocardial wall. Small amounts of fluid $(<20$ $\mathrm{mL}$ ) can be detected with a high sensitivity. Pleural effusion and epicardial fat may be sometimes mistaken for pericardial effusion. As a rule, fluid appearing in the parasternal long-axis view anterior to the descending aorta is typically pericardial, while pleural effusion is usually localized posterior to the aorta. Fat is naturally distinguished from effusion by a higher density (brighter echoes). As for pericardial thickening, distinction between fat and pericardium may require the use of other imaging techniques.

Echocardiographic features suggestive of cardiac tamponade may occur, but are rare. They are discussed elsewhere. ${ }^{44}$ Characteristic echocardiographic findings of constrictive pericarditis include thick ened pericardium, prominent respiratory phasic diastolic bounce of the inter-ventricular septum, restrictive diastolic filling pattern (E/A ratio of $>2$ and deceleration time of the mitral E-velocity of $<140 \mathrm{~ms}$ ), significant inspiratory variation of the mitral E-wave velocity $(>25 \%)$, diastolic flattening of the LV posterior wall, inferior vena cava plethora, and expiratory diastolic flow reversal in the hepatic veins. Typically, tissue Doppler interrogation of the medial mitral annulus reveals a normal or increased velocity that can be higher than the lateral annulus velocity. ${ }^{45}$ The systolic pulmonary pressures are not significantly elevated. ${ }^{44}$ This condition may be differentiated from restrictive cardiomyopathy (also a complication of radiation) by the normal mitral tissue Doppler velocity and a systolic pulmonary artery pressure $<50 \mathrm{mmHg}^{46}$

Cardiac MR.-In acute pericarditis, pericardial layers are typically thickened and strongly enhance following contrast administration. ${ }^{47}$ Pericardial enhancement reflects inflammation and correlates with elevated inflammatory markers (Figure 2). ${ }^{48-50}$ The presence, location, and extent of pericardial effusion, as well as associated cardiac tamponade, can be well assessed using a combination of dark blood and bright-blood CMR sequences, and to some extent the characterization of pericardial effusion can be achieved. The location and severity of pericardial abnormalities is well visualized using black blood, $T_{1}$-weighted fast spin-echo CMR, though it should be emphasized that pericardial calcifications might be missed. CMR allows the detection of indirect signs of constrictive pericarditis, such as unilateral or bilateral atrial enlargement, conical deformity of the ventricles, dilatation of caval/hepatic veins, pleural effusion, and ascites. End-stage chronic forms of constrictive pericarditis may not demonstrate pericardial LGE on CMR, whereas pericardial enhancement is suggestive of residual inflammation. Although pericardial thickness is traditionally considered an important criterion for constrictive pericarditis, it is important to note that the range of pericardial thicknesses is highly variable (1-17 mm, mean of $4 \mathrm{~mm}$ ) with up to $20 \%$ of patients showing a normal thickness $(<2 \mathrm{~mm})$. Two recent studies showed that pericardial thickness in end-stage constrictive pericarditis was significantly lower than in those with persistent chronic inflammation and no signs of constriction. ${ }^{49,50}$ Real-time cine imaging is of great value to assess the impact of respiration on the inter-ventricular septal shape and motion, allowing to easily depict pathological (increased) ventricular coupling. ${ }^{51}$ Furthermore, tagging the sequence detects the presence of pericardial adhesion. Recently, real-time phase-contrast imaging has been proposed to assess the effects of respiration on cardiac filling. ${ }^{52}$

Cardiac CT.-The pericardial cavity and membranes are between the epicardial and pericardial fat and can be recognized on cardiac CT 

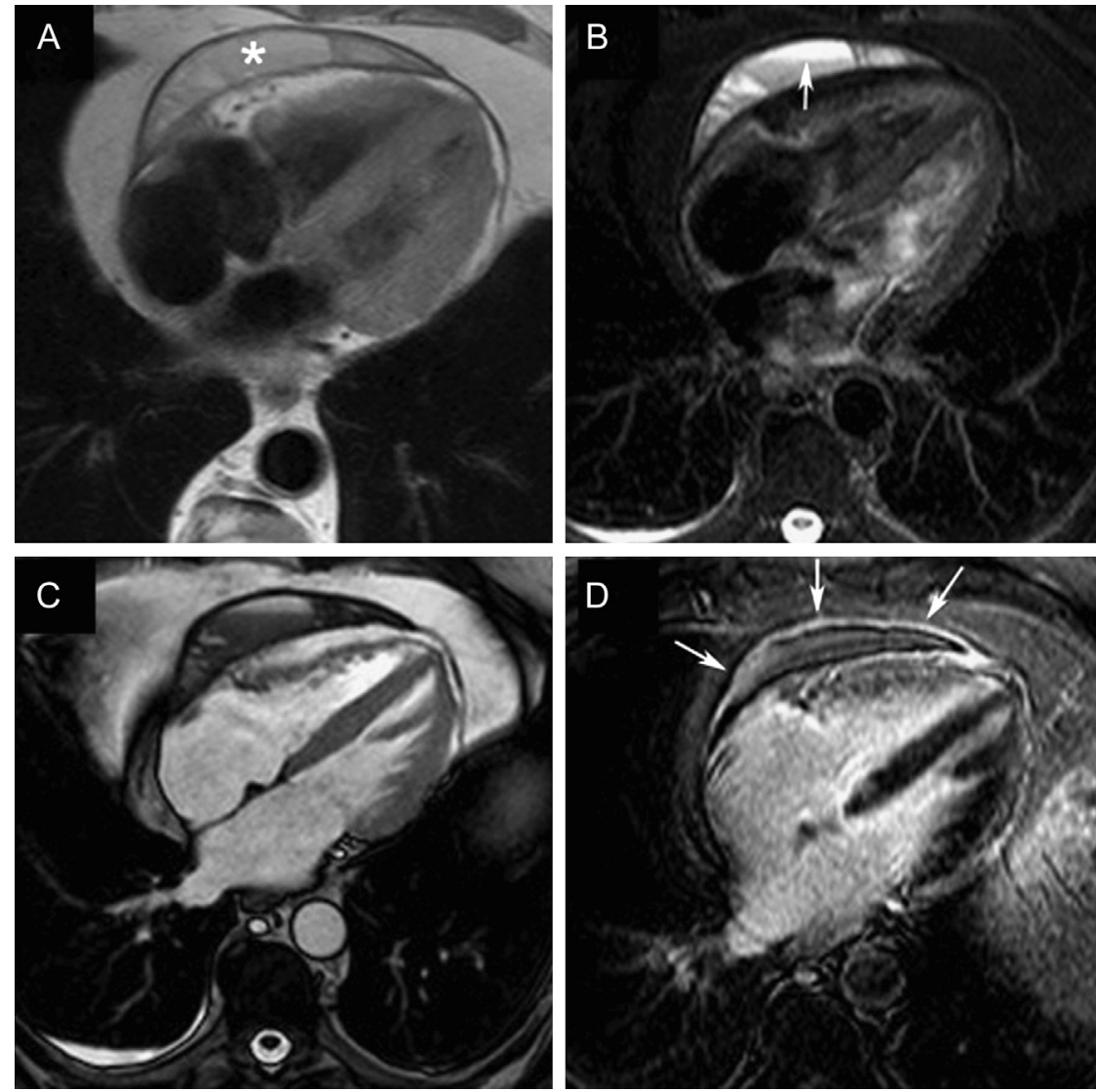

Figure 2 Inflammatory-effusive constrictive pericarditis in 67-year-old man presenting with increasing complaints of dyspnoea. Transthoracic and transoesophageal echocardiography were inconclusive to rule out pericardial pathology. Dark-blood, $T_{1}$-weighted (A), and $T_{2}$-weighted STIR (B) fast spin-echo CMR, CMR (C), and LGE CMR (D). Loculated pericardial effusion (asterisk, A) with several fibrous layers, fluid-fluid level (arrow, B), several fibrous strands, and thickened appearance of the pericardial layers strongly enhancing the following administration of gadolinium contrast agent (arrows, D). The compression of the right ventricular free wall is well visible on CMR (C). Real-time CMR (additional movie) shows inspiratory septal inversion with an increased total respiratory septal shift confirming constrictive component. Pericardiectomy was performed showing chronically inflamed and fibrotically thickened pericardial layers with a collection of old blood.

images even without injection of contrast media. The normal pericardium is clearly visible near the right ventricle (RV) and generally does not measure $>3 \mathrm{~mm}$ in thickness (Figure $3 \mathrm{~A}$ ). Thickening of the pericardium (Figure 3B) may be difficult to distinguish from small pericardial effusions. Inflamed pericardial membranes may have increased attenuation, compared with the pericardial fluid (Figure 3C). Pericardial calcifications (Figure 3D), as well as larger pericardial effusion, are readily identified, and also, on non-enhanced CT images. Based on the measured attenuation, serous transudates (0-25 HU) and non-serous exudates $(>25 \mathrm{HU})$ may be differentiated. Cardiac tamponade may be suggested by large fluid accumulation, compression of the cardiac cavities, and right-sided venous congestion. Constrictive pericarditis is not an anatomical diagnosis, although certain CT characteristics are associated, such as pericardial calcification, pericardial thickening $(>4 \mathrm{~mm})$, narrowing or tubular deformation of the RV, as well as manifestations of venous congestion. Pericardial abnormalities may be regional (Figure 4).

LV Systolic and Diastolic Dysfunction. The assessment of myocardial systolic and diastolic function during radiotherapy using traditional and advanced imaging strategies does not differ in principle from that used in other diseases. This document therefore refers to the respective joint publications of the European Association of
Cardiovascular Imaging (EACVI) and ASE, ${ }^{23,25,44}$ and to consensus reports of clinical experts in CMR, cardiac CT, and nuclear cardiology. ${ }^{40,53}$ One particular challenge for all imaging techniques in this particular clinical setting, however, is the importance of reproducible measurements. Serial examination used to monitor the cardiac side effects of cancer treatments are commonly done by different examiners using different machines, which require high quality acquisition to allow meaningful comparisons.

The common imaging findings of radiation-induced myocardial dysfunction include limited regional wall-motion abnormalities (often inferior in location) or mild global LV hypokinesia, depressed LV systolic function, impaired myocardial relaxation, and diastolic dys function.

Conventionally, cardiotoxicity is monitored by measuring the LV ejection fraction. One crucial issue, however, is that the definition of cardiotoxicity varies between studies. It may include an ejection fraction decline of $>20 \%$ (EF units), a decrease of LV ejection fraction by $>10$ points to $<55 \%$, or a drop of LV ejection fraction $<45 \%$. ${ }^{54}$ As it has been reported in patients treated with chemotherapy, ${ }^{26,27} \mathrm{LV}$ ejection fraction is rather insensitive for detecting subtle alterations in myocardial function in early radiation-induced cardiotoxicity. ${ }^{55}$ Furthermore, the value of LV ejection fraction in predicting the occurrence of later cardiomyopathy in patients treated with chemotherapy 


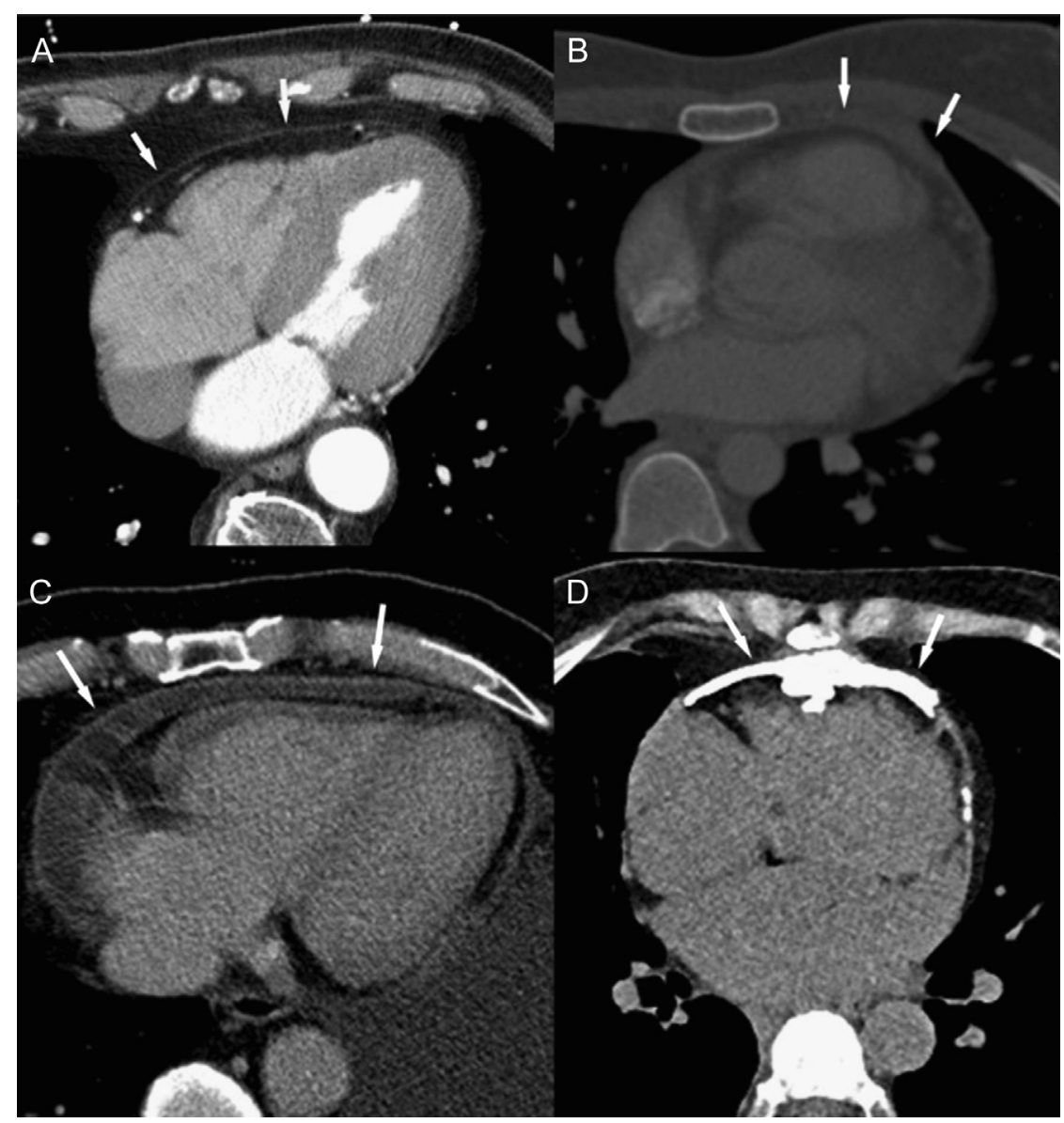

Figure 3 Cardiac CT of the pericardium: Normal pericardium (A), thickened pericardium (B), pericardial effusion and hyper-enhanced pericardial layers (C), and pericardial calcification (D).

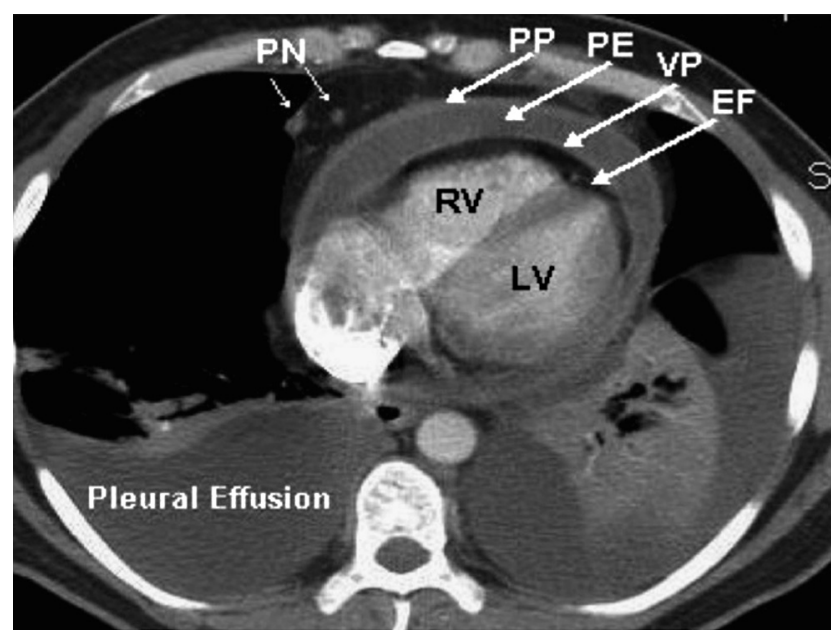

Figure 4 Cardiac CT. Pericardial effusion: parietal pericardium (PP), pericardial effusion (PE), visceral pericardium (VP), epicardial fat $(E F)$, right ventricle (RV), left ventricle (LV), and pericardial lymph nodes (PN).

and radiotherapy is debated. ${ }^{56}$ Nearly all patients with systolic dysfunction have some degree of concomitant diastolic dysfunction, especially impaired relaxation, and variable decreases in ventricular compliance. In the study of Heidenreich et al., ${ }^{57}$ the prevalence of di- astolic dysfunction in asymptomatic patients after mediastinal radiation was 14\%. The authors showed that patients with LV diastolic dysfunction had decreased cardiac event-free survival and were more likely to have stress-induced ischaemia than those with normal diastolic function. However, the clinical value of diastolic parameters in the detection of radiation-induced cardiomyopathy remains unproven. The presence of diffuse myocardial fibrosis in radiationinduced myocardial injury is likely to have important repercussions on diastolic function. An early study of 24 patients with Hodgkin's disease treated by non-anthracycline chemotherapy and radiotherapy reported more frequent diastolic than systolic impairment. ${ }^{58}$ However, a more recent study comparing 20 patients with leftsided breast cancer and 10 with right-sided breast cancer did not demonstrate any difference in diastolic parameters between the two groups of patients. $^{26}$

Echocardiography.-Global and regional LV systolic function: While LV ejection fraction assessment by echocardiography can be regarded as the standard in global systolic function assessment during radiotherapy, subtle changes, particularly due to early treatment effects, may be missed due to measurement variability. As a drawback, the routinely used 2D echocardiographic LV ejection fraction assessment is image quality-dependent and its inter- and intra-observer variability are reported around 9 and 7\%, respectively. ${ }^{59} 3 \mathrm{D} \mathrm{LV} \mathrm{ejection} \mathrm{fraction}$ is better correlated with CMR-derived ejection fraction in cancer survivors. ${ }^{60} \mathrm{~A}$ new, tracking-based ejection fraction analysis method 


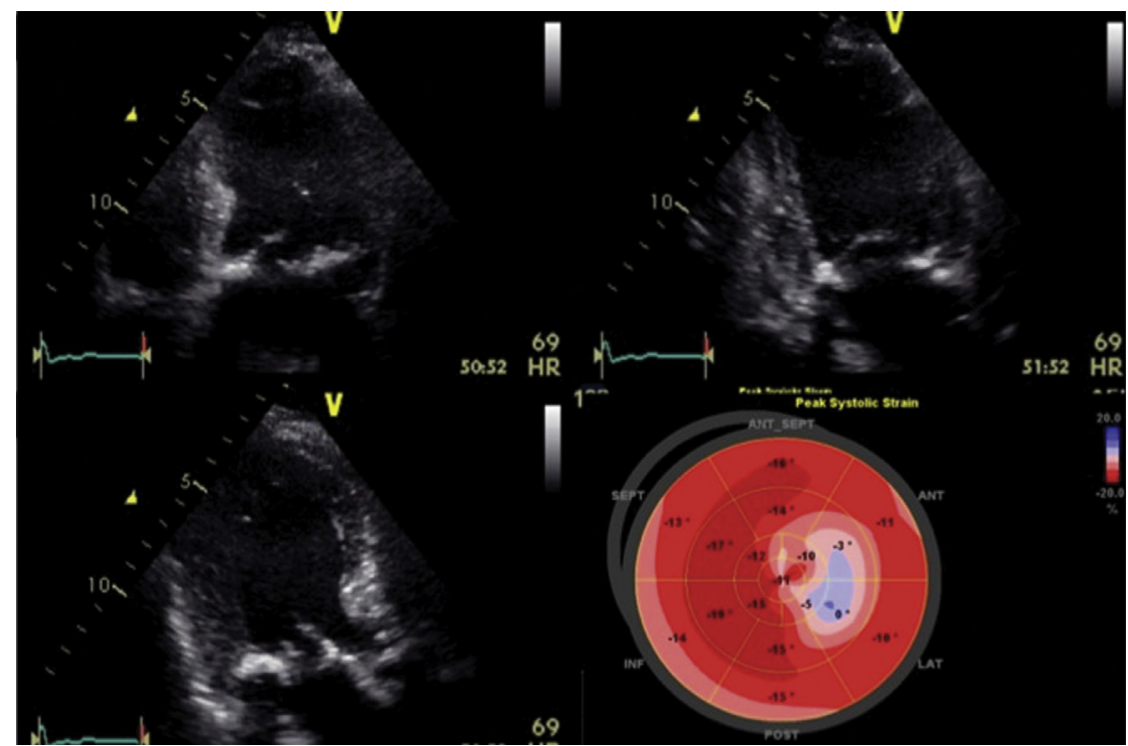

Figure 5 Echocardiography. Longitudinal left ventricular (LV) function assessed by 2D speckle tracking imaging of a patient with radiation-induced valvular heart disease and LV dysfunction. LV ejection fraction was normal while a Bull's eye plot of LV longitudinal strain (lower right panel) demonstrates impaired regional longitudinal function (light colours).

(auto ejection fraction) has been shown to significantly reduce inter-observer variability, ${ }^{61}$ which is of particular importance in the follow-up of oncology patients. Findings from chemotherapy trials repeatedly demonstrate that deformation parameters can detect subtle function changes missed by the LV ejection fraction. ${ }^{62}$ Furthermore a decrease in peak longitudinal systolic strain was reported to predict the occurrence of later cardiotoxicity. ${ }^{63}$ Recently, a study in Hodgkin's survivors reported that global longitudinal systolic strain was able to differentiate patients receiving radiotherapy from those receiving both radiotherapy and chemotherapy, whereas LV ejection fraction did not. ${ }^{55}$ Similarly, in a study with 20 left-sided breast cancer patients, ${ }^{26,64}$ without any measurable alteration of the LV ejection fraction immediately after radiotherapy, strain imaging could clearly detect a correlation between the reduction in regional myocardial function and the local radiation dose (Figures 5 and 6). These abnormalities persisted during the entire 14-month follow-up period.

$L V$ diastolic function: Although both systolic and diastolic dysfunction often occur together, ${ }^{65}$ the distinction between the two components may be necessary to determine the treatment strategy of a symptomatic patient. LV diastolic function is commonly evaluated by conventional Doppler (mitral inflow, pulmonary venous flow) and tissue Doppler techniques (applied to mitral annulus motion). However, it is important to note that diastolic parameters are highly sensitive to any change in the loading conditions.

Cardiac MR.-CMR is an adequate alternative technique to assess LV function in patients with poor acoustic windows. Bright-blood cine imaging using the SSFP technique is an accurate and reproducible technique to assess ventricular volumes, mass, and systolic function longitudinally. ${ }^{66}$ The heart is studied comprehensively using both short- and long-cardiac axes, allowing a set of images completely covering the $L V{ }^{28}$ This feature enables a volumetric assessment of both the LV and right ventricle with the calculation of end-diastolic and end-systolic volumes, myocardial mass, and functional parameters such as ejection fraction. The same set of images can be used to assess regional contractility and contractile patterns. The 17-segment model as proposed by the American Heart Association, can be recommen- ded for structured reporting of regional LV function. ${ }^{67}$ CMR assess ment of diastolic function emulates to a large extent Doppler echocardiography by measuring the flow over the atrio-ventricular valves and in the caval and pulmonary veins with phase-contrast CMR. Subtle disturbances in myocardial contraction/relaxation patterns not discernible by conventional CMR techniques can be depicted by means of CMR myocardial tagging, strain-encoded CMR, and phase-contrast velocity imaging. ${ }^{37,68-70}$ Hitherto, no studies have demonstrated their clinical value in radiation-induced myocardial dysfunction.

Cardiac CT.-Cardiac CT is not the first-choice technique for the as sessment of ventricular contractile function because of the availability of good alternatives, with higher temporal resolution, that do not require radiation or administration of contrast agents (echocardiography and CMR). However, when echocardiography and CMR are technically complicated or unavailable, CT can assess the global left and right ventricular function accurately and reproducibly. The accuracy of cardiac CT in comparison with CMR for the assessment of LV dimensions, global contractile function, and mass is good. ${ }^{71}$ The assessment of the global right ventricular function is also possible. ${ }^{72}$ The temporal resolution of cardiac CT is currently in the range of 75-175 ms, which allows the evaluation of regional contractile function of the LV. ${ }^{73}$ Higher radiation doses are needed to acquire fullcardiac cycle datasets for LV functional assessment that limits the use of cardiac CT for serial assessment of LV function. Conversely, lower doses of radiation are needed to evaluate the coronary calcium score, which is increased in case of CAD. However, to date, no studies have evaluated the usefulness of this approach for screening patients with CAD.

Nuclear Cardiology.-Radionuclide ventriculography (RNV), either by the equilibrium or the first-pass method, is an accurate tool to as sess and quantify LV systolic and diastolic function at rest and during conditions of stress (for the equilibrium method). The advantage of RNV is the ability to quantify ventricular volumes from total radioactive count density without the need for calculating volumes from $2 \mathrm{D}$ 


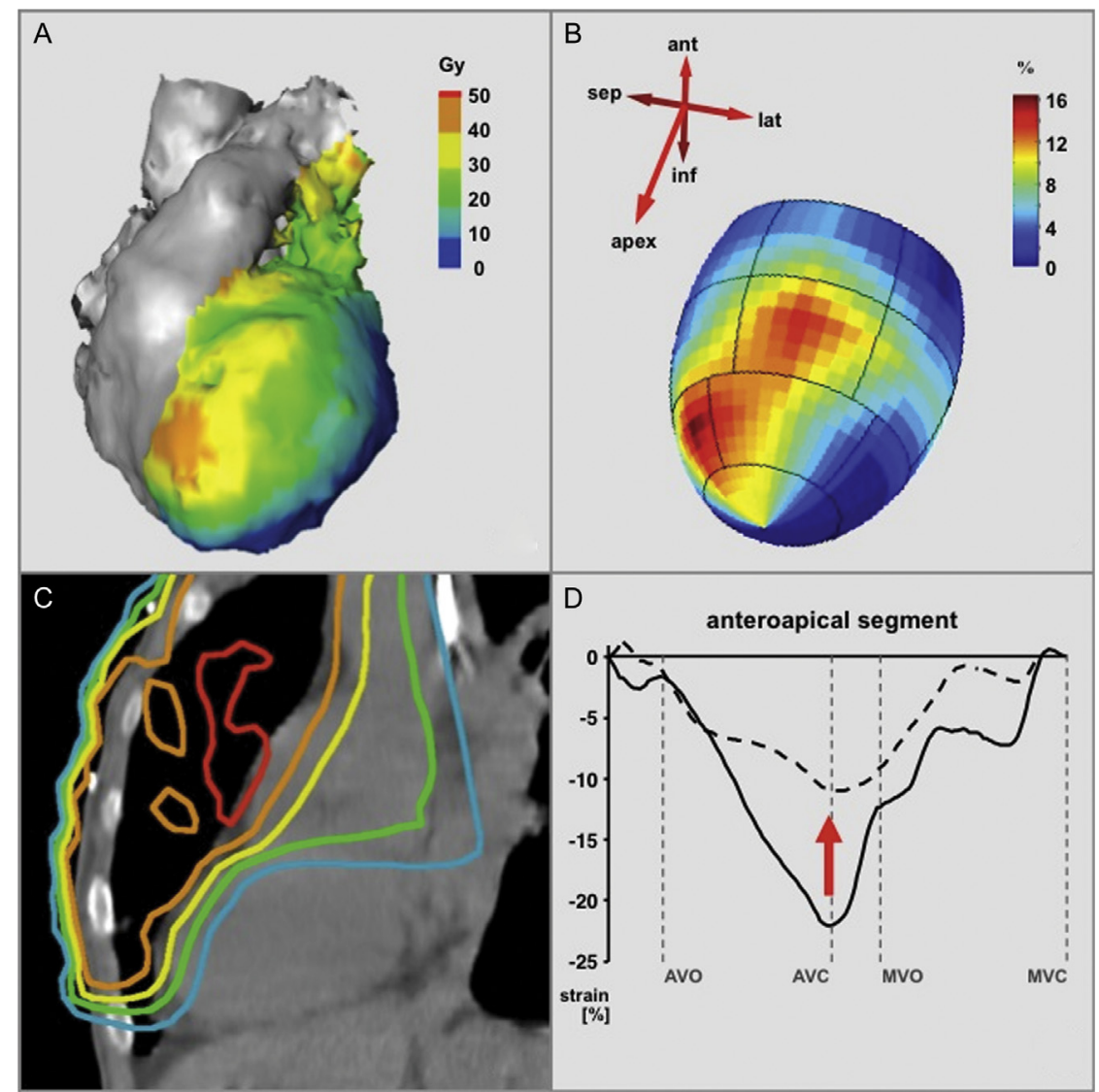

Figure 6 Echocardiography. Acute radiation effects on regional myocardial function: comparison between radiation dose distribution (A and $\mathbf{B})$ and regional myocardial function decrease measured by tissue Doppler-derived longitudinal myocardial strain (C and $\mathbf{D})$ after radiotherapy in a patient with left-sided breast cancer. Note the regional concordance between irradiated area and regional dysfunction (modified from Jurcut et al. ${ }^{64}$ ).

slices using geometrical assumptions about LV geometry. Diastolic function ${ }^{74}$ can be assessed by acquiring data with high temporal resolution and by calculating the peak filling rate and time-to-peak filling rate. Nevertheless, due to its radiation exposure and the availability of other imaging techniques (i.e. echocardiography), RNV has virtually disappeared in the majority of centres for the assessment of ventricular function and volumes. One small study employed RNV to assess LV function after mediastinal irradiation in 15 subjects. An ejection fraction was lower than in controls and a further decrease in ejection fraction could be observed in five subjects with exercise. ${ }^{75}$ Using ECG-gated acquisitions of myocardial perfusion SPECT, LV volumes and ejection fraction can be obtained. This allows assessing myocardial perfusion and LV function in the same setting.

Restrictive Cardiomyopathy. Echocardiography.-The classical restrictive cardiomyopathy is characterized by increased stiffness of the myocardium and a small LV with an increased left atrial size. This causes an early rapid rise in LV pressure during LV filling. Systolic function assessed by traditional echocardiographic techniques is usually normal. Doppler measurements of the transmitral flow reveal a typical pattern consisting of a short mitral $\mathrm{E}$ deceleration duration and a low A wave velocity resulting in a high $\mathrm{E} / \mathrm{A}$ ratio. ${ }^{44}$ The $\mathrm{E}^{\prime}$-wave by tissue Doppler imaging is usually decreased. The corresponding finding during invasive catheterization is the dip-plateau pattern of early diastolic pressure traces. A combined occurrence of constrictive pericarditis and restrictive cardiomyopathy may lead to a more difficult interpretation of the transmitral LV filling pattern. A constellation of findings, consisting of decreased mean LV mass, end-diastolic dimension, and end-diastolic wall thickness together with self-reported dyspnoea, is also suggestive of restrictive cardiomyopathy in this population. ${ }^{76}$

Cardiac MR.-Restrictive cardiomyopathy occurs as a result of diffuse myocardial fibrosis. Several recent studies have underscored the potential of $T_{1}$ mapping by CMR to depict diffuse myocardial fibrosis. $T_{1}$ mapping can be used to quantify the concentration of gadolinium-based extracellular contrast agents in the myocardium and in the blood pool. ${ }^{34,35}$ This information can be used to derive the extracellular volume of the myocardium, which is directly related to collagen content. ${ }^{77}$ Although this technique holds promise to be used as an in vivo marker for diffuse myocardial fibrosis, its role in radiation-related myocardial fibrosis is still unclear.

Cardiac CT.-Cardiac CT in the diagnosis of restrictive cardiomyopathy after radiotherapy has little value. Dilation of both atria in the presence of a small LV chamber in a patient with chest radiation therapy, symptoms of heart failure, and without any history of atrial fibrillation might raise the suspicion of restrictive cardiomyopathy. The disease has to be confirmed or ruled out by echocardiography or CMR.

Nuclear Cardiology.-There is no proven value of nuclear cardiology in the detection of restrictive cardiomyopathy after radiation exposure. 
Valvular Heart Disease. Echocardiography.-There are distinct echocardiographic characteristics of radiation-induced valve disease. ${ }^{46,78-80}$ These include fibrosis and calcification of the aortic root, aortic valve annulus, aortic valve leaflets, aortic-mitral inter-valvular fibrosa, mitral valve annulus, and the base and mid-portions of the mitral valve leaflets. Typically, these modifications spare the mitral valve tips and commissures. ${ }^{78}$ The fibrosis and calcification may be contiguous or randomly dispersed (Figure 7). ${ }^{16}$ It should be noted that structural deterioration of the aortic and mitral valve with fibrosis, calcification, and resultant valve dysfunction may occur also in patients with chronic uraemia or haemodialysis. ${ }^{80}$ In such patients, premature valve disease might be related to secondary hyperparathyroidism, hypertension, and hypercholesterolaemia, ${ }^{81}$ as well as to altered bone tissue metabolism and metastatic calcification. ${ }^{82}$ Another differential diagnosis, when co-existent of mitral and aortic valve disease is present, is rheumatic valve disease. The main distinguishing features between radiation-induced valve disease and rheumatic heart disease would be the presence of commissural fusion and involvement of the mitral leaflet tips with rheumatic disease, which is not found with radiation. ${ }^{78} 3 \mathrm{D}$ echocardiography is particularly useful for the assessment of the presence or absence of commissural fusion and should be used in situations where there is incomplete visualization of the mitral commissures by $2 \mathrm{D}$ echocardiography. ${ }^{79}$ Drug-induced valvulopathies from ergots, methysergide, or anorexigens such as fenfluramine and phentermine share the following similarities: mitral and aortic valve thickening, mitral valve leaflet tethering by shortened chordae with the predominant consequence being valvular regurgitation. ${ }^{83}$ Soliciting a history of such use of these drugs is important in making the diagnosis.

Grading the severity of valvular disease should be based on the guidelines from the European Association of Cardiovascular Imaging and the American Society of Echocardiography, ${ }^{84-87}$ and the reader is referred to these guidelines for details. In RIHD, the following considerations are made:

(i) Mitral stenosis is graded as mild, moderate, or severe based on the mitral valve area, mitral valve diastolic Doppler gradient, and pulmonary hypertension. Planimetry of the mitral valve may not be feasible because of severe calcification. Planimetry of the mitral valve area at the leaflet tips may also underestimate the severity of stenosis since the leaflet tips are spared and there is no commissural fusion. The presence of restrictive cardiomyopathy with significant underlying diastolic dysfunction may lead to shortened pressure half time and overestimation of the mitral valve area by this method. In addition, increased LVend-diastolic pressure may lead to elevated mitral $\mathrm{E}$-wave resulting in elevated time velocity integral of the mitral inflow CW Doppler signal, which will result in an elevated mean diastolic Doppler gradient tracing. Pulmonary hypertension may be the result of diastolic dysfunction and not necessarily a consequence of mitral valve stenosis.

(ii) Aortic stenosis is graded as mild, moderate, or severe based on the aortic valve area, aortic mean Doppler gradient, and aortic valve peak systolic velocity. In these patients, a potential confounding factor is the presence of significant LV systolic dysfunction, which by reducing forward stroke volume may lead to underestimation of aortic stenosis severity. Of note, a low-flow state can also be observed in patients with the preserved LV ejection fraction. When the LV ejection fraction is reduced, dobutamine stress echocardiography can help differentiate pseudo-severe from fixed severe aortic stenosis.

(iii) Mitral and aortic regurgitation is graded as mild, moderate, or severe based on a combination of quantitative and qualitative parameters. The calculation of the regurgitant volume and effective regurgitant orifice area should be attempted on all patients. The assessment of the severity of mitral valve regurgitation can be difficult in the presence of significant mitral annular calcification because of acoustic shadowing and difficulties with measuring the diameter of the mitral annulus. Transoesophageal echocardiography is particularly useful in the assessment of mitral valve disease when there is significant mitral valve annulus calcification.

(iv) Right-sided valve disease (tricuspid and pulmonary valve regurgitation and pulmonary stenosis) is uncommon, but may also occur as a result of radiation. Tricuspid valve regurgitation may also be a consequence of left-sided valve disease or RV dysfunction. Grading of the severity of right-sided valve disease should also follow the guidelines on the assessment of valvular regurgitation and stenosis.

Cardiac MR.-In patients with inadequate echocardiographic quality or discrepant results, CMR can be used for comprehensive assessment of valvular heart disease. CMR provides both anatomical and dynamic evaluation of the diseased valve, including information on the number of leaflets, valve thickness, valve structure, leaflet mobility, and valve orifice. ${ }^{28}$ Valvular dysfunction can be quantified by measuring the degree of valvular stenosis (the measurement of transvalvular gradients, assessment of aortic valve area) and/or valvular regurgitation (the measurement of regurgitant volumes and fraction) ${ }^{88}$ and by assessing its impact on cardiac chambers shape, size, and function as well as on the great vessels. ${ }^{88}$ Cardiac MR is more robust and better validated for evaluating pulmonic valve regurgitation and less robust for the evaluation of mitral and tricuspid valves.

Cardiac CT.-Cardiac CT provides high-resolution, cross-sectional, and $3 \mathrm{D}$ information of the cardiac valves, particularly during the relatively quiescent end-systolic and end-diastolic phases of the cardiac cycle. Degenerative valvular disease is morphologically characterized by thickening of the valve leaflet with calcific deposits. Dynamic imaging is more challenging, and CT is not well able to assess the functional significance of valvular disease. In general populations, the ability of CT to measure the stenotic aortic valve area has been demonstrated, with good correlation with transoesophageal ultrasound. ${ }^{89}$ Also in aortic regurgitation, planimetry of the regurgitant orifice has been studied in comparison with echocardiography and demonstrated good diagnostic performance to rule out moderate-to-severe aortic regurgitation. ${ }^{90}$ Planimetry of the aortic valve area may be challenging due to excessive calcification of the valve leaflets. Associated abnormalities of aortic valve disease, such as aortic root dilatation, LV hypertrophy, or dilatation, may be assessed by CT. CT may image all morphological hallmarks of mitral stenosis and can be useful in selected patients with poor acoustic windows, in whom percutaneous intervention is considered. In mitral regurgitation, CT can show incomplete closure of the mitral valve leaflets and may even allow planimetry of the regurgitant orifice of the leaking valve. ${ }^{91}$ Rightsided valves are more difficult to assess when the mixture of contrast medium is incomplete. Healthy tricuspid and pulmonary valves are thin and not well visible, in comparison with thickened valves.

Coronary Artery Disease. Echocardiography.-The value of rest echocardiography in CAD is limited to the assessment of the presence and extent of regional wall-motion abnormalities. In asymptomatic patients, moderate-to-severe hypokinesia has been found in up to $17 \%$ of survivors with Hodgkin's disease treated with mediastinal irradiation $(\geq 35 \mathrm{~Gy}) .{ }^{17}$ However, a hypokinetic ventricular region is not necessarily characteristic of the presence of $\mathrm{CAD}$, but could reflect, to some extent, myocardial disease process. Stress-induced wall-motion abnormality is a reliable indicator of transient myocardial ischaemia which is highly sensitive and specific for angiographically assessed epicardial coronary artery stenosis. Either dobutamine or exercise 


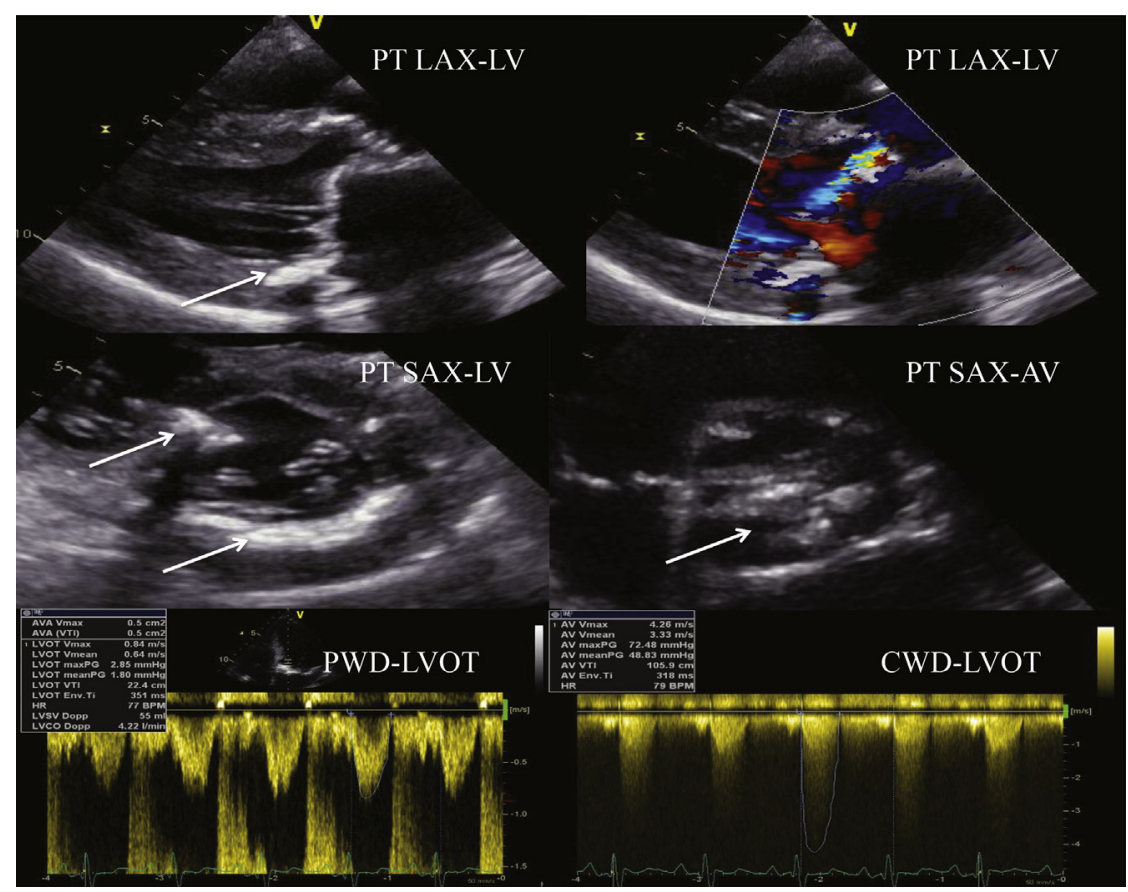

Figure 7 Echocardiography. Example of a patient with radiation-induced valvular heart disease. Extensive calcifications of the aortic and mitral valve (arrows) and of the left ventricle. Significant aortic stenosis and regurgitation.

echocardiography can be used. Exercise testing is, however, the recommended test in patients able to exercise. No study has evaluated the value of dipyridamole stress echocardiography, in this setting. The specific details of protocols, interpretation, and diagnostic criteria of these tests are previously published in the European and American expert consensus statement on stress echocardiography. ${ }^{92,93}$ Inducible ischaemia is characterized by new or worsening wallmotion abnormality. Location, extent, and ischaemic threshold should be reported. Of note, interpretation of the test depends on the presence of an adequate acoustic window, which can adversely affect its overall accuracy. In a recent study enrolling 294 asymptomatic patients with Hodgkin's disease treated with mediastinal irradiation ( $\geq 35 \mathrm{~Gy}$ ), Heidenreich et al., using stress echocardiography (exercise and dobutamine), have reported a $2.7 \%$ prevalence of severe three-vessel or left main CAD, and a 7.5\% prevalence of coronary stenosis $>50 \%$. Positive predictive values for stress echocardiography were 80 and $87 \%$ for detecting $\geq 70$ and $50 \%$ coronary stenosis, respectively. In that study, after a median of 6.5-year follow-up, 23 patients developed symptomatic CAD, including 10 who sustained an acute myocardial infarction. The risk of a cardiac event after screening was related to, among other things, the presence of resting wall-motion abnormalities on echocardiography and ischae mia on stress testing. ${ }^{94}$

Cardiac MR.-CMR is able to directly image epicardial coronary artery stenosis, microvasculature on myocardial perfusion, ventricular function, and viability. With the advent of fast and reliable coronary artery imaging with cardiac CT, CMR is relegated to clinical assessment in younger patients for entities such as anomalous coronary vessels. ${ }^{95}$ Reversible myocardial ischaemia can be assessed through stress-induced myocardial perfusion and/or function. ${ }^{96}$ Usually, a pharmacologic agent such as adenosine or dobutamine is used. In a recent prospective trial in 752 patients (non-radiation related), stress perfusion CMR was superior to SPECT in detecting haemodynami- cally significant stenosis. ${ }^{97}$ In the last decade, CMR has emerged as the gold standard to evaluate myocardial infarction in both acute and chronic settings. In a recent CMR study, in 20-year survivors of Hodgkin's diseases, perfusion defects were found in $68 \%$ and late myocardial enhancement in $29 \%$ of patients. ${ }^{88}$

Cardiac CT.-With cardiac CT, imaging of coronary calcium does not require injection of contrast medium. In the general population, coronary calcium is associated with an adverse outcome and could be of help for risk stratification. As in other groups of patients, obstructive CAD is probably rare in the absence of detectable calcium after irradiation. ${ }^{98,99}$ Whether coronary calcium has a comparable prognostic value or might serve as a gatekeeper to further testing after radiation therapy is currently unknown (Figure 8). The diagnostic performance of coronary CT has been extensively studied in comparison with invasive angiography. In meta-analyses limited to 64+ slice CT technology, the per-patient sensitivity and specificity for coronary CT angiography range between $98-100$ and $82-91 \%$, respectively, using invasive angiography as reference. ${ }^{100}$ Because of the high negative predictive value and the inability to assess the haemodynamic significance of detected obstructions, coronary CT angiography is mostly used to rule out the presence of CAD. Impaired image quality and excessive calcification (combined with residual motion artefacts) are as sociated with overestimation of the severity of the obstructive disease. Coronary CT angiography has been used for follow-up in small groups of patients after radiation therapy for Hodgkin's disease. These studies demonstrated advanced coronary calcification and advanced obstructive CAD in relatively young patients. ${ }^{75,101}$ From the available data, it is unclear whether CT could distinguish general atherosclerotic CAD from lesions caused by radiation therapy. In the absence of symptoms of CAD, there is currently insufficient data to recommend a routine use of coronary CT angiography in patients who underwent high-dose radiation therapy. New CT applications to assess the haemodynamic significance of coronary stenosis, 


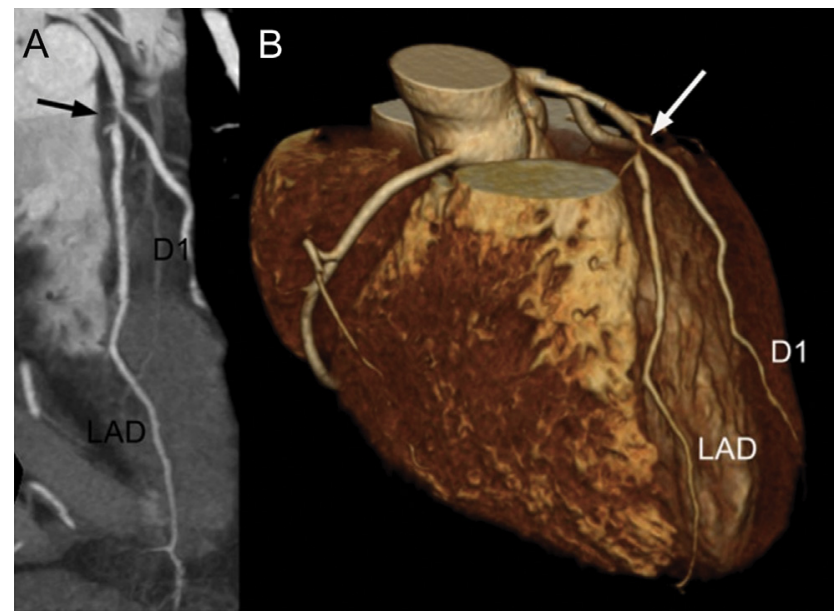

Figure 8 Cardiac CT. CAD: a 41-year-old man with severe obstructive coronary disease of the left anterior-diagonal bifurcation (arrow) only a few years after mediastinal radiation therapy because of Hodgkin's lymphoma by angiographic (A) and CCT (B) imaging.

including stress myocardial perfusion CT and computer-simulated fractional flow reserves based on CT angiography, are currently under development. ${ }^{102}$ Similar to CMR, late contrast enhancement by CT can be demonstrated after myocardial infarction. ${ }^{103}$ However, CMR remains the modality of choice for identifying myocardial infarction and scars.

Nuclear Cardiology.-Radionuclide imaging (SPECT and PET) was introduced in the 1970s and 1980s as an accurate and robust technique to assess myocardial perfusion. The prevalence of myocardial perfusion defects among long-term survivors of chest irradiation for cancers varied widely $(>1-64 \%)$, depending on the volume of the LV in the radiotherapy field, age and timing of screening, and scintigraphic methods used (planar scintigraphy in older studies vs. tomographic methods [SPECT] with higher sensitivity in more recent studies). ${ }^{76,104}$ Marks et al. ${ }^{105}$ initiated a prospective study to assess changes in myocardial perfusion and function following irradiation of left-sided breast cancer. Patients underwent preradiotherapy and serial 6-month post-radiotherapy resting cardiac SPECT scans. The incidence of myocardial perfusion abnormalities increased over time from $27 \%$ at 6 months to $42 \%$ at 24 months after radiotherapy. A non-significant change in the LV ejection fraction was apparent only in patients with relatively large areas of perfusion defects. Repeated scanning, 3-8 years after radiotherapy, of patients already showing perfusion abnormalities at an earlier scan demonstrated that perfusion defects persisted. ${ }^{106}$ Although the clinical significance of these perfusion defects is unknown, they appear to be associated with abnormalities in wall motion and episodes of chest pain. ${ }^{105}$

In patients with distal oesophageal cancer, radiotherapy has been shown to be associated with a high prevalence of inducible inferior LV ischaemia. ${ }^{107}$ Maunoury et al. reported abnormal exercise ${ }^{201} \mathrm{Tl}$ perfusion patterns in $84 \%$ of 31 asymptomatic patients. However, in many of these patients, the distribution pattern did not match with a typical coronary territory, thereby, suggesting a disease of the microvasculature rather than of epicardial vessels. ${ }^{108}$ Pierga et al. reported similar results with the anterior myocardial wall affected in the majority of patients (86\%). In a recent study, the prevalence of stress-induced perfusion abnormalities increased from $5 \%$, to $11 \%$, and $20 \%$ in the $2-10$ years, $11-20$ years, and $>20$ years after irradiation, respectively. ${ }^{109}$ In that study, myocardial ischaemia on SPECT was shown to be associated with a higher risk for subsequent coronary events, and prompted myocardial revascularization in a substantial proportion of patients. There are limited data comparing the accuracy of different imaging modalities to detect CAD in patients af ter mediastinal irradiation. In one small head-to-head comparison, SPECT had the highest sensitivity compared with stress echocardiography (65 vs. 59\%) and stress-ECG, albeit at the cost of a higher falsepositive rate ( 89 vs. $11 \%$ ). Many of these false-positive findings may actually be caused by microvascular disease, endothelial dysfunction, or vascular spasm. ${ }^{94}$

Myocardial perfusion PET can be used to evaluate the presence of microvascular dysfunction, which has been demonstrated to add an incremental prognostic value in a variety of cardiac conditions. ${ }^{42}$ However, in the setting of mediastinal radiation, no data have been published so far.

\section{Peripheral Artery Disease (in Particular Carotid Arteries).} Ultrasound Imaging.-Carotid artery ultrasound is very useful to detect increased intima-media thickness and carotid stenosis after radiotherapy. An increase of the intima-media thickness has been found in $24 \%$ of 42 patients with Hodgkin's disease who underwent radiation therapy $>5$ years before. This observation has been recently confirmed in patients undergoing radiation therapy for non-Hodgkin's lymphoma and seminoma. ${ }^{110}$ Of note, carotid lesions secondary to radiotherapy are often more extensive and commonly involve longer segments of the carotid arteries.

Vascular MR.-Contrast-enhanced MR angiography is the most widely used and valuable CMR technique for imaging the great vessels. ${ }^{28}$ Besides 3D angiographic techniques using the first pass of contrast through the vessels, newly available time-resolved ('4D') approaches that allow display of vascular filling in a similar manner to conventional X-ray angiography are of interest. ${ }^{111}$ Additionally, black- and bright-blood CMR sequences can be applied to describe the morphology of the arterial lesions, while phase-contrast imaging enables the assessment of flow patterns over the stenosis. ${ }^{28}$

Vascular CT.-CT angiography (Figure 9) is routinely used to evaluate carotid, sub-clavian, and aortic diseases related to radiation therapy. Of particular interest is the screening, before any cardiac surgery, for porcelain aorta, not an unusual finding in patients 10-20 years after radiotherapy.

\section{RECOMMENDATIONS FOR CLINICAL APPLICATIONS}

\section{Screening and Comprehensive Follow-up Evaluation}

The published data on RIHD argue in favour of a comprehensive long-term follow-up to develop potential strategies to reduce the risk of RIHD development. As the epidemiological studies do not give clues on the important mechanisms underlying RIHD, it is difficult to design preventive strategies. Alteration in radiotherapy field or targeted radiation, with avoidance and/or shielding of the heart, remains one of the most important interventions to prevent RIHD. ${ }^{3}$ Patients with classical cardiovascular risk factors should be treated aggressively. Modifying risk factors such as weight, lack of exercise, smoking and hypertension, as well as early detection and treatment of RIHD may improve the long-term cardiovascular outcome. ${ }^{17,20}$ In the absence of risk factors, the value of primary and secondary prevention is debateable. 


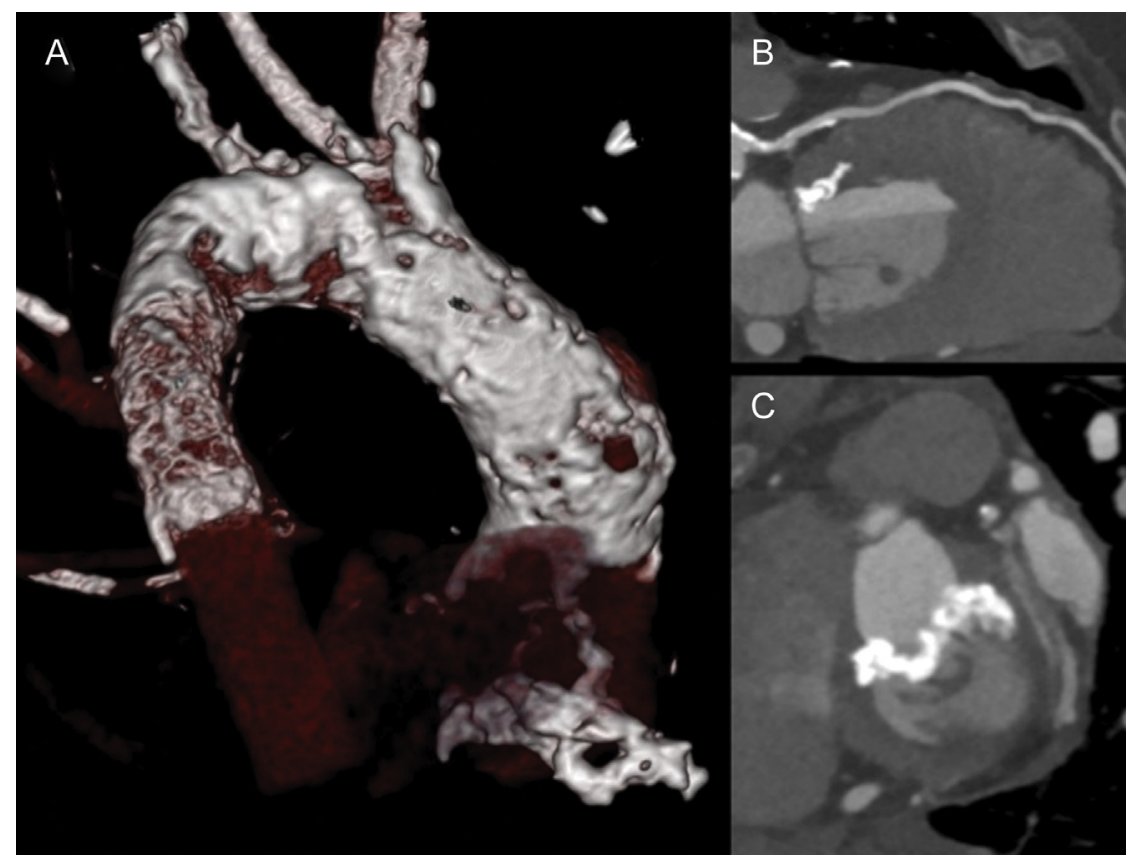

Figure 9 Cardiac CT. Cardiovascular disease after radiation therapy: extensive vascular disease of the aorta and brachiocephalic branches, CAD that required bypass graft surgery and mitral valve disease in a 35-year-old woman who underwent extensive mediastinal radiation therapy because of Hodgkin's lymphoma at the age of 7 .

Despite the insights gathered from recent studies, little is known about the prevalence of preclinical heart disease following thoracic irradiation and whether asymptomatic patients would benefit from systematic screening. There are no accepted guidelines for comprehensive cardiovascular screening and surveillance after exposure to ionizing radiation. The efforts in the field should aim at better identifying the patients at higher risk of RIHD. Although most clinical information about the cardiac effects of thoracic radiation is based on studies of patients with breast cancer or Hodgkin's disease, ${ }^{5,7,8}$ RIHD can also be observed in survivors of lung or oesophageal cancer. ${ }^{107,108}$ Younger age, cardiovascular risk factors or pre-existing cardiovascular diseases, exposure to high doses of radiation $>30$ Gy), concomitant chemotherapy, anterior or left chest irradiation location (Hodgkin's lymphoma $>$ left-sided breast cancer $>$ rightsided breast cancer), and the absence of shielding designate highest risk and such patients are likely to benefit most from screening. In ad dition, the prevalence and severity of these abnormalities increase considerably over time from 5 to 20 years, making a strong argument for screening because they are often clinically unrecognized. Although screening of patients at risk for RIHD is necessary, the optimal methods and frequency remain unclear. To assess cardiac structural and functional changes after radiation exposure, clinicians will have to use available techniques such as echocardiography, CMR, CT, or SPECT meaningfully within the appropriate clinical indication (Table 4). All this will enable patient-specific clinical-decision making.

Pericardial Disease. Echocardiography is the first-line imaging in patients with suspected or confirmed pericardial disease. ${ }^{112,113}$ Serial echocardiography is helpful in patients presenting with pericardial effusion or constrictive pericarditis to aid in the timing and selection of the appropriate management strategy. Although echocardiography is the modality of choice in constrictive and effusive pericardial pathophysiology, it is less useful for diagnosing pericardial thickening and calcifications. More sensitive techniques, such as cardiac CT and CMR, have proven to be more efficient in the detection of specific anatomical abnormalities. Whether CMR or CT can be effective for serial examination is unknown.

Myocardial Dysfunction. Myocardial damage is frequent in cancer survivors treated with radiation therapy. ${ }^{57,114}$ Echocardiography is a useful, non-invasive, and repeatable method to identify and monitor LV systolic and diastolic dysfunctions. Dobutamine stress echocardiography can be used to check contractile reserve in order to identify and follow over time sub-clinical LV dysfunction. CMR is the method of choice in patients with poor acoustic windows while cardiac CT and RNV represent potential alternatives. However, LV ejection fraction alone does not provide all the relevant clinical information. In patients with the preserved LVejection fraction, reduced longitudinal function as evaluated by 2D speckle tracking global strain, ${ }^{55,64}$ patchy distribution of myocardial fibrosis on CMR, ${ }^{35,112}$ and abnormal myocardial perfusion on SPECT ${ }^{105}$ all represent markers of an intrinsic myocardial disease progression. Early detection of these abnormalities may allow the initiation of tailored treatment. The timing and frequency of these tests for serial assessment are still to be determined. ${ }^{55}$

Valvular Heart Disease. Echocardiography is highly sensitive in detecting any degree of valvular heart disease. In the first 10 years post-radiation, mild left-sided valve regurgitation is a frequent observation. ${ }^{114-116}$ However, the clinical significance of mild disease remains unclear since treatment is not affected, endocarditis prophylaxis is no longer required (unless the patient has had previous endocarditis), and progression to severe valvular heart disease may take many years. Haemodynamically significant ( $\geq$ moderate valve disease) is more common $>10$ years following radiation, ${ }^{9}$ and some studies suggested a higher incidence and prevalence of valve disease in women than men. ${ }^{17}$ Current ESC and ACC/ AHA guidelines recommend surveillance transthoracic echocardiog raphy in the management of valve disease. ${ }^{117,118}$ 
Table 4 Practical use of imaging techniques for the detection and follow-up of RIHD

\begin{tabular}{|c|c|c|c|c|c|}
\hline & Echocardiography & Cardiac CMR & Cardiac CT & Stress echocardiography & ERNA/SPECT perfusion \\
\hline \multicolumn{6}{|l|}{ Pericardial disease } \\
\hline $\begin{array}{l}\text { Effusion-screening and } \\
\text { positive diagnosis }\end{array}$ & ++++ & + & + & - & $+/-$ \\
\hline Effusion-follow-up & ++++ & - & - & - & $+/-$ \\
\hline $\begin{array}{l}\text { Constriction-screening } \\
\text { and positive diagnosis }\end{array}$ & ++++ & ++++ & ++ & - & $+/-$ \\
\hline \multicolumn{6}{|l|}{ Myocardial disease } \\
\hline LV systolic dysfunction & $\begin{array}{l}++++ \text { (first-line imaging, } \\
\text { contrast echocardiography } \\
\text { if poor acoustic window) }\end{array}$ & ++++ & + & $\begin{array}{l}++++ \text { (contractile reserve } \\
\text { assessment) }\end{array}$ & $\begin{array}{l}++++/++++ \text { (used when both } \\
\text { function and perfusion are to } \\
\text { be analysed) }\end{array}$ \\
\hline LV diastolic dysfunction & ++++ & + & - & - & $++/+$ \\
\hline LV dysfunction-follow-up & $\begin{array}{l}++++ \text { (first-line imaging, } \\
\text { contrast echocardiography } \\
\text { if poor acoustic window) }\end{array}$ & + & - & $\begin{array}{l}++ \text { (contractile reserve } \\
\quad \text { assessment) }\end{array}$ & $++/++$ \\
\hline Myocardial fibrosis & - & ++++ & + & - & - \\
\hline \multicolumn{6}{|l|}{ Valve disease } \\
\hline $\begin{array}{r}\text { Positive diagnosis and } \\
\text { severity assessment }\end{array}$ & ++++ & ++ & - & ++ & $+/-$ \\
\hline Follow-up & ++++ & - & - & ++ & $+/-$ \\
\hline \multicolumn{6}{|l|}{ Coronary artery disease } \\
\hline Positive diagnosis & $\begin{array}{l}+ \text { (if resting wall-motion } \\
\text { abnormalities) }\end{array}$ & $++++\left(\right.$ stress $\left.\mathrm{CMR}^{\mathrm{b}}\right)$ & $++\left(\right.$ CT angio $\left.{ }^{a}\right)$ & $\begin{array}{c}++++(\text { exercise or } \\
\left.\text { dobutamine }^{b}\right)\end{array}$ & $+/++++$ \\
\hline Follow-up & + & + & - & ++++ (first-line imaging) & $+/++$ \\
\hline
\end{tabular}

Angio, Angiography; $C M R$, cardiac magnetic resonance; $C T$, computed tomography; $E R N A$, equilibrium radionuclide angiocardiography; $L V$, left ventricle; $S P E C T$, single-photon emission CT.

++++ , Highly valuable; ++ , valuable; + , of interest; - , of limited interest.

${ }^{a}$ For anatomical evaluation, an excellent negative predictive value.

${ }^{b}$ For functional evaluation. 


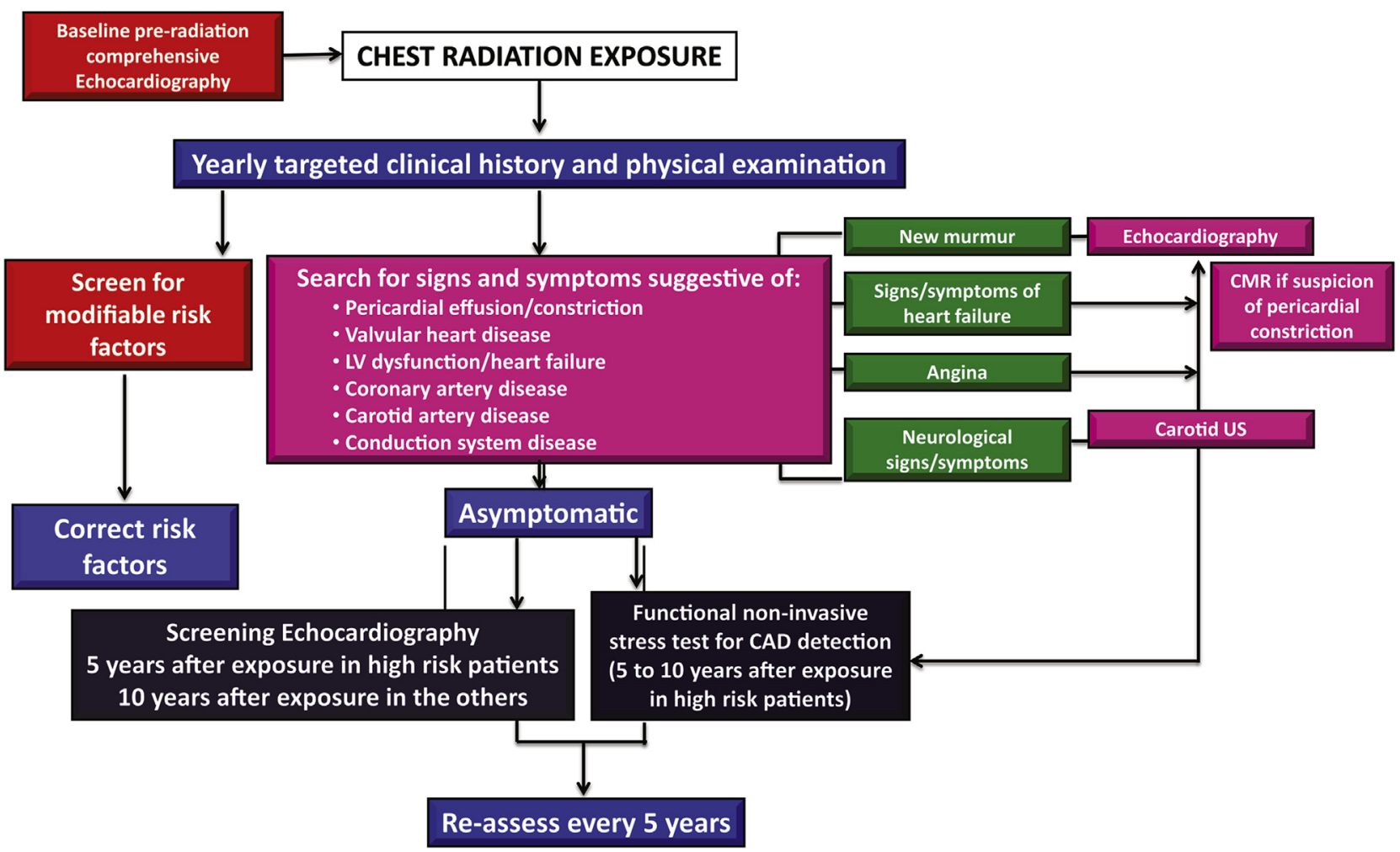

Figure 10 Algorithm for patient management after chest radiotherapy. $L V$, Left ventricle; US, ultrasound. High-risk patients: refer to Table 1. Modifiable risk factors refer to: hypertension, tobacco use, hypercholesterolaemia, obesity, and diabetes.

Coronary Artery Disease. Patients with radiation-induced CAD generally present at younger age than the general population. The time interval for the development of significant CAD is $\sim 5-10$ years. ${ }^{16,116,119}$ Tests of inducible ischaemia, such as stress echocardiography, perfusion SPECT, and CMR, are recognized techniques to unmask the functional consequences of CAD. Image-based stress testing is indicated in irradiated patients who are symptomatic for angina or who develop new resting regional wall-motion abnormalities on a follow-up echocardiogram. ${ }^{92}$ In asymptomatic patients, although all techniques have roughly comparable diagnostic values, inducible perfusion abnormality is not necessarily corroborated with significant CAD, which may make perfusion SPECT less reliable for screening CAD. ${ }^{94}$ Recent studies have emphasized the potential interest in using CT calcium score or angiography for the evaluation of the presence of coronary lesions. However, there are currently insufficient data to recommend a systematic use of these new tools after chest irradiation. Cardiac CT is, however, highly valuable for the detection of porcelain aorta in the pre-operative setting, particularly if a cardiac surgery is contemplated. Manipulation or clamping of a porcelain aorta was proved to be associated with a very high risk of either cerebral or systemic embolism during cardiac surgery. Thus, pre-operative screening for porcelain aorta is required in high-risk patients (Table 1). The best current imaging modality to screen for a porcelain aorta is cardiac CT. Pre-operatively, the non-invasive imaging of the internal thoracic artery conduits after mediastinal irradiation does not seem to be justified, as histomorphologic investigations did not identify any severe irradiation-induced graft damage. ${ }^{120}$ Although, cardiac CT or CMR may image retrosternal adhesions prior cardiac surgery, no specific recommendations can be drawn from the literature in patients with previous chest irradiation.

\section{Practical Use of Imaging Studies for Follow-up Evaluation}

The following statements are based on a consensus of experts and refer to the available published data. Although the magnitude of the risk of RIHD with modern radiotherapy techniques is not yet well defined, screening and follow-up examinations are warranted. Indeed, the risk of LV dysfunction, valvular abnormality, and CAD remains consequential in patients treated in the $1980 \mathrm{~s}$ with chest irradiation. A pre-treatment cardiovascular screening for risk factors and a careful clinical examination should be performed in all patients. A baseline comprehensive echocardiographic evaluation is warranted in all patients before initiating the radiotherapy, which aims to identify any cardiac abnormalities. During follow-up, a yearly history and physical examination with close attention to symptoms and signs of heart disease that might otherwise be overlooked in this generally young population is essential. The development of either new cardiopulmonary symptoms or new suggestive physical examination findings, such as a new murmur, should prompt transthoracic echocardiography examination. In patients who remain asymptomatic, screening echocardiography 10 years after treatment appears reasonable given the high likelihood of diagnosing significant cardiac pathology. In cases where there are no pre-existing cardiac abnormalities, surveillance transthoracic echocardiogram should be performed every 5 years after the initial 10-year echocardiographic screening examination following radiation. In high-risk asymptomatic patients (patients who underwent anterior or left-side chest irradiation with $\geq 1$ risk factors for RIHD, Table 1), a screening echocardiography may be advocated af ter 5 years. In these patients, the increased risk of coronary events 5 -10 years after radiotherapy makes it reasonable to consider noninvasive stress imaging to screen for obstructive CAD. Repeated stress testing can be planned every 5 years if the first exam does not show 
inducible ischaemia. Because of its higher specificity compared with exercise ECG, stress echocardiography or stress CMR may be preferred. Repeated stress nuclear imaging may be possible if the radiation exposure is $<5 \mathrm{mSv}$. A short algorithm for patient management after thoracic radiotherapy is presented in Figure 10. Of note, stress scintigraphy should be used cautiously for follow-up studies due to the cumulative radiation exposure. ${ }^{121}$ The additional role of CMR or cardiac CT depends on the initial echocardiographic results and the clinical indication as well as the local expertise and facilities. Currently, there are no data justifying their use as screening tools, except, in high-risk patients, for the detection of porcelain aorta in the pre-operative cardiac setting. However, when the echocardiographic examination yields equivocal findings, these imaging modalities should be considered.

\section{CONCLUSION AND FUTURE DIRECTIONS}

There is compelling evidence that chest radiotherapy can increase the risk of heart disease. Although modern radiotherapy techniques are likely to reduce the prevalence and severity of RIHD, the incidence of RIHD is expected to increase in cancer survivors who have re ceived old radiotherapy regimens. Improved knowledge of the prevalence of RIHD will help the medical community to better evaluate and inform patients of the risk of RIHD after chest radiotherapy. The adequate strategy for screening of RIHD remains a source of debate in the radiation and medical oncology community. Large prospective studies are required to confirm the clinical utility of non-invasive imaging for comprehensive screening and surveillance of asymptomatic cancer survivors. This will enable targeted followup, screening, and intervention.

\section{NOTICE AND DISCLAIMER}

This report is made available by EACVI and American Society of Echocardiography (ASE) as a courtesy reference source for members. This report contains recommendations only and should not be used as the sole basis to make medical practice decisions or for disciplinary action against any employee. The statements and recommendations contained in this report are primarily based on the opinions of experts, rather than on scientifically verified data. EACVI and ASE make no express or implied warranties regarding the completeness or accuracy of the information in this report, including the warranty of merchantability or fitness for a particular purpose. In no event shall EACVI or ASE be liable to you, your patients, or any other third parties for any decision made or action taken by you or such other parties in reliance on this information. Nor does your use of this information constitute the offering of medical advice by EACVI and ASE or create any physician-patient relationship between EACVI/ASE and your patients or anyone else.

\section{REFERENCES}

1. Baker JE, Moulder JE, Hopewell JW. Radiation as a risk factor for cardiovascular disease. Antioxid Redox Signal 2011;15:1945-56.

2. Aleman BMP, van den Belt-Dusebout AW, Klokman WJ, Van't Veer MB, Bartelink $H$, van Leeuwen FE. Long-term cause-specific mortality of patients treated for Hodgkin's disease. J Clin Oncol 2003;21:3431-9.
3. Darby SC, Cutter DJ, Boerma M, Constine LS, Fajardo LF, Kodama K, et al. Radiation-related heart disease: current knowledge and future prospects. Int J Radiat Oncol Biol Phys 2010;76:656-65.

4. Roger VL, Go AS, Lloyd-Jones DM, Berry JD, Borden WB, Bravata DM, et al. Heart disease and stroke statistics-2012 update: a report from the American Heart Association. Circulation 2012;125:e2-220.

5. Schultz-Hector S, Trott KR. Radiation-induced cardiovascular diseases: is the epidemiologic evidence compatible with the radiobiologic data? Int ] Radiat Oncol Biol Phys 2007;67. 10-8.

6. Wu W, Masri A, Popovic ZB, Smedira NG, Lytle BW, Marwick TH, et al. Long-term survival of patients with radiation heart disease undergoing cardiac surgery: a cohort study. Circulation 2013;127:1476-84.

7. Hancock S, Tucker M, Hoppe R. Factors affecting late mortality from heart disease after treatment of Hodgkin's disease. JAMA 1993;270: 1949-55.

8. Clarke M, Collins R, Darby S, Davies C, Elphinstone P, Evans E, et al., Early Breast Cancer Trialists' Collaborative Group. Effects of radiotherapy and of differences in the extent of surgery for early breast cancer on local recurrence and 15-year survival: an overview of the randomised trials. Lancet 2005;366:2087-106.

9. Carver JR, Shapiro CL, Ng A, Jacobs L, Schwartz C, Virgo KS, et al., ASCO Cancer Survivorship Expert Panel. American Society of Clinical Oncology clinical evidence review on the ongoing care of adult cancer survivors: cardiac and pulmonary late effects. J Clin Oncol 2007;25: 3991-4008.

10. Darby SC, Ewertz M, McGalle P, Bennet AM, Blom-Goldman U, Bronnum D, et al. Risk of ischemic heart disease in women after radiotherapy for breast cancer. N Engl J Med 2013;368:987-98.

11. Darby S, McGale P, Taylor C, Peto R. Long-term mortality from heart disease and lung cancer after radiotherapy for early breast cancer: prospective cohort study of about 300000 women in US SEER cancer registries. Lancet Oncol 2005;6:557-65.

12. Marhin W, Wai E, Tyldesley S. Impact of fraction size on cardiac mortality in women treated with tangential radiotherapy for localized breast cancer. Int J Radiat Oncol Biol Phys 2007;69:483-9.

13. Meyer R, Gospodarowicz M, Connors J, Pearcey R, Wells W, Winter J, et al., NCIC Clinical Trials Group, Eastern Cooperative Oncology Group. ABVD alone versus radiation-based therapy in limited-stage Hodgkin's lymphoma. N Engl J Med 2012;366:399-408.

14. Shapiro C, Hardenbergh P, Gelman R, Blanks D, Hauptman P, Recht A, et al. Cardiac effects of adjuvant doxorubicin and radiation therapy in breast cancer patients. J Clin Oncol 1998;16:3493-501.

15. Hooning M, Botma A, Aleman B, Baaijens M, Bartelink H, Klijn J, et al. Long-term risk of cardiovascular disease in 10-year survivors of breast cancer. J Natl Cancer Inst 2007;99:365-75

16. King V, Constine L, Clark D, Schwartz R, Muhs A, Henzler M, et al Symptomatic coronary artery disease after mantle irradiation for Hodgkin's disease. Int J Radiat Oncol Biol Phys 1996;36:881-9.

17. Heidenreich P, Kapoor J. Radiation induced heart disease: systemic disorders in heart disease. Heart 2009;95:252-8.

18. Boerma M, Hauer-Jensen M. Preclinical research into basic mechanisms of radiation-induced heart disease. Cardiol Res Pract 2011;2011: http://dx.doi.org/10.4061/2011/858262. Article ID 858262, 8 pages.

19. Stewart F, Hoving S, Russell N. Vascular damage as an underlying mechanism of cardiac and cerebral toxicity in irradiated cancer patients. Radiat Res 2010; 174:865-9.

20. Yusuf S, Sami S, Daher I. Radiation-induced heart disease: a clinical update. Cardiol Res Pract 2011; http://dx.doi.org/10.4061/2011/317659. Article ID 317659, 9 pages.

21. Stewart F, Heeneman S, Te Poele J, Kruse J, Russell N, Gijbels M, et al. Ionizing radiation accelerates the development of atherosclerotic lesions in $\mathrm{ApoE}^{-1-}$ mice and predisposes to an inflammatory plaque phenotype prone to hemorrhage. Am J Pathol 2006; 168:649-58.

22. Evangelista A, Flachskampf F, Lancellotti P, Badano L, Aguilar R, Monaghan $\mathrm{M}$, et al., European Association of Echocardiography. European Association of Echocardiography recommendations for 
standardization of performance, digital storage and reporting of echocardiographic studies. Eur J Echocardiogr 2008;9:438-48.

23. Lang R, Badano L, Tsang W, Adams D, Agricola E, Buck T, et al., American Society of Echocardiography, European Association of Echocardiography. EAE/ASE recommendations for image acquisition and display using three-dimensional echocardiography. Eur Heart J Cardiovasc Imaging 2012;13:1-46.

24. Senior R, Becher H, Monaghan M, Agati L, Zamorano I, Vanoverschelde J, et al. Contrast echocardiography: evidence-based recommendations by European Association of Echocardiography. Eur J Echocardiogr 2009;10:194-212.

25. Mor-Avi V, Lang R, Badano L, Belohlavek M, Cardim N, Derumeaux G et al. Current and evolving echocardiographic techniques for the quantitative evaluation of cardiac mechanics: ASE/EAE consensus statement on methodology and indications endorsed by the Japanese Society of Echocardiography. Eur J Echocardiogr 2011;12:167-205

26. Erven K, Jurcut R, Weltens C, Giusca S, Ector J, Wildiers H, et al. Acute radiation effects on cardiac function detected by strain rate imaging in breast cancer patients. Int J Radiat Oncol Biol Phys 2011;79:1444-51.

27. Edvardsen T, Helle-Valle T, Smiseth O. Systolic dysfunction in heart failure with normal ejection fraction: speckle-tracking echocardiography. Prog Cardiovasc Dis 2006;49:207-14.

28. Bogaert J, Dymarkowski S, Taylor AM, Muthurangu V. Clinical Cardiac MRI. 2nd ed. Heidelberg, Germany: Springer; 2012

29. Simonetti O, Finn J, White R, Laub G, Henry D. 'Black blood' $T_{2}$ weighted inversion-recovery MR imaging of the heart. Radiology 1996; 199:49-57.

30. Francone M, Carbone I, Agati L, Bucciarelli Ducci C, Mangia M, Iacucci I, et al. Utility of $T_{2}$-weighted short-tau inversion recovery (STIR) sequences in cardiac MRI: an overview of clinical applications in ischaemic and non-ischaemic heart disease. Radiol Med 2011;116:32-46.

31. Giri S, Chung YC, Merchant A, Mihai G, Rajagopalan S, Raman S, et al. $T_{2}$ quantification for improved detection of myocardial edema. J Cardiovasc Magn Reson 2009;11:56.

32. Simonetti O, Kim R, Fieno D, Hillenbrand H, Wu E, Bundy J, et al. An improved MR imaging technique for the visualization of myocardial infarction. Radiology $2001 ; 218: 215-23$.

33. Mahrholdt H, Wagner A, Judd R, Sechtem U, Kim R. Delayed enhancement cardiovascular magnetic resonance assessment of non-ischaemic cardiomyopathies. Eur Heart I 2005;26:1461-74

34. Flett A, Hayward M, Ashworth M, Hansen M, Taylor A, Elliott $P$, et al. Equilibrium contrast cardiovascular magnetic resonance for the measure ment of diffuse myocardial fibrosis: preliminary validation in humans. Circulation 2010;122:138-44.

35. Jellis C, Martin J, Narula J, Marwick T. Assessment of nonischemic myocardial fibrosis. J Am Coll Cardiol 2010;56:89-97.

36. Barkhausen J, Ruehm S, Goyen M, Buck T, Laub G, Debatin J. MR evaluation of ventricular function: true fast imaging with steady-state preces sion versus fast low-angle shot cine MR imaging: feasibility study. Radiology $2001 ; 219: 264-9$.

37. Zerhouni E, Parish D, Rogers W, Yang A, Shapiro E. Human heart: tagging with MR imaging-a method for noninvasive assessment of myocardial motion. Radiology 1988;169:59-63.

38. Chai P, Mohiaddin R. How we perform cardiovascular magnetic resonance flow assessment using phase-contrast velocity mapping. J Cardiovasc Magn Reson 2005;7:705-16.

39. Von Ballmoos M, Haring B, Juillerat $P$, Alkadhi H. Meta-analysis: diagnostic performance of low-radiation-dose coronary computed tomography angiography. Ann Intern Med 2011;154:413-20.

40. Klocke F, Baird M, Lorell B, Bateman T, Messer J, Berman D, et al., American College of Cardiology, American Heart Association, American Society for Nuclear Cardiology. ACC/AHA/ASNC guidelines for the clinical use of cardiac radionuclide imaging executive summary: a report of the American College of Cardiology/American Heart Association Task Force on Practice Guidelines (ACC/AHA/ASNC Committee to Revise the 1995 Guidelines for the Clinical Use of Cardiac Radionuclide Imaging). J Am Coll Cardiol 2003;42:1318-33.
41. Duvall WL, Croft LB, Godiwala T, Ginsberg E, George T, Henzlova MJ. Reduced isotope dose with rapid SPECT MPI imaging: initial experience with a CZT SPECT camera. J Nucl Cardiol 2010;17:1009-14.

42. Camici P, Crea F. Coronary microvascular dysfunction. N Engl J Med 2007;356:830-40.

43. Galiuto L, Badano L, Fox K, Sicari R, Zamorano JL. The EAE Textbook of Echocardiography. Oxford: Oxford University Publishing; 2011.

44. Nagueh S, Appleton C, Gillebert T, Marino P, Oh J, Smiseth O, et al. Recommendations for the evaluation of left ventricular diastolic function by echocardiography. Eur J Echocardiogr 2009;10:165-93.

45. Reuss CS, Wilansky SM, Lester SJ, Lusk JL, Grill DE, Oh JK, et al. Using mitral 'annulus reversus' to diagnose constrictive pericarditis. Eur J Echocardiogr 2009; 10:372-5

46. Hamza A, Tunick P, Kronzon I. Echocardiographic manifestations of complications of radiation therapy. Echocardiography 2009;26: 724-8.

47. Taylor A, Dymarkowski S, Verbeken E, Bogaert J. Detection of pericardial inflammation with late-enhancement cardiac magnetic resonance imaging: initial results. Eur Radiol 2006;16:569-74.

48. Feng D, Glockner J, Kim K, Martinez M, Syed I, Araoz P, et al. Cardiac magnetic resonance imaging pericardial late gadolinium enhancement and elevated inflammatory markers can predict the reversibility of constrictive pericarditis after antiinflammatory medical therapy: a pilot study. Circulation 2011;124:1830-7.

49. Zurick A, Bolen M, Kwon D, Tan C, Popovic Z, Rajeswaran J, et al. Pericardial delayed hyperenhancement with CMR imaging in patients with constrictive pericarditis undergoing surgical pericardiectomy: a case series with histopathological correlation. JACC Cardiovasc Imaging 2011; 4:1180-91.

50. Giorgi B, Mollet N, Dymarkowski S, Rademakers F, Bogaert J. Clinically suspected constrictive pericarditis: MR imaging assessment of ventricular septal motion and configuration in patients and healthy subjects. Radiology $2003 ; 228: 417-24$

51. Francone M, Dymarkowski S, Kalantzi M, Rademakers F, Bogaert J. Assessment of ventricular coupling with real-time cine MRI and its value to differentiate constrictive pericarditis from restrictive cardiomyopathy. Eur Radiol 2006;16:944-51.

52. Thavendiranathan P, Verhaert D, Walls M, Bender J, Rajagopalan S, Chung YC, et al. Simultaneous right and left heart real-time, free-breathing CMR flow quantification identifies constrictive physiology. JACC Cardiovasc Imaging 2012;5:15-24.

53. Hendel R, Patel M, Kramer C, Poon M, Hendel R, Carr I, et al. ACCF/ ACR/SCCT/SCMR/ASNC/NASCI/SCAI/SIR 2006 appropriatenes criteria for cardiac computed tomography and cardiac magnetic resonance imaging: a report of the American College of Cardiology Foundation Quality Strategic Directions Committee Appropriateness Criteria Working Group, American College of Radiology, Society of Cardiovascular Computed Tomography, Society for Cardiovascular Magnetic Resonance, American Society of Nuclear Cardiology, North American Society for Cardiac Imaging, Society for Cardiovascular Angiography and Interventions, and Society of Interventional Radiology. J Am Coll Cardiol 2006;48:1475-97.

54. Seidman A, Hudis C, Pierri M, Shak S, Paton V, Ashby M, et al. Cardiac dysfunction in the trastuzumab clinical trials experience. J Clin Oncol 2002;20:1215-21.

55. Tsai HR, Gjesdal O, Wethal T, Haugaa K, Fossa A, Fossa S, et al. Left ventricular function assessed by two-dimensional speckle tracking echocardiography in long-term survivors of Hodgkin's lymphoma treated by mediastinal radiotherapy with or without anthracycline therapy. Am J Cardiol 2011;107:472-7.

56. Swain S, Whaley F, Ewer M. Congestive heart failure in patients treated with doxorubicin: a retrospective analysis of three trials. Cancer 2003 97:2869-79.

57. Heidenreich P, Hancock S, Vagelos R, Lee B, Schnittger I. Diastolic dys function after mediastinal irradiation. Am Heart J 2005;150:977-82.

58. Ilhan I, Sarialioglu F, Ozbarlas N, Buyukpamukcu M, Akyuz C, Kutluk T. Late cardiac effects after treatment for childhood Hodgkin's disease with 
chemotherapy and low-dose radiotherapy. Postgrad Med J 1995;71 164-7.

59. Chuang M, Hibberd M, Salton C, Beaudin R, Riley M, Parker R, et al. Im portance of imaging method over imaging modality in noninvasive determination of left ventricular volumes and ejection fraction: assessment by two- and three-dimensional echocardiography and magnetic resonance imaging. J Am Coll Cardiol 2000;35:477-84

60. Armstrong G, Plana J, Zhang N, Srivastava D, Green D, Ness K, et al. Screening adult survivors of childhood cancer for cardiomyopathy: comparison of echocardiography and cardiac magnetic resonance imaging. I Clin Oncol 2012;30:2876-84.

61. Szulik M, Pappas C, Jurcut R, Magro M, Peeters E, Goetschalckx K, et al. Clinical validation of a novel speckle-tracking-based ejection fraction assessment method. J Am Soc Echocardiogr 2011;24: 1092-100.

62. Ganame I, Claus P, Eyskens B, Uyttebroeck A, Renard M, D'hooge J, et al. Acute cardiac functional and morphological changes after Anthracycline infusions in children. Am J Cardiol 2007;99:974-7.

63. Sawaya H, Sebag I, Plana J, Januzzi J, Ky B, Tan T, et al. Assessment of echocardiography and biomarkers for the extended prediction of cardiotoxicity in patients treated with anthracyclines, taxanes, and trastuzumab. Circ Cardiovasc Imaging 2012;5:596-603.

64. Jurcut R, Ector J, Erven K, Choi H, Voigt JU. Radiotherapy effects on systolic myocardial function detected by strain rate imaging in a left-breast cancer patient. Eur Heart J 2007;28:2966.

65. Stoodley P, Richards D, Boyd A, Hui R, Harnett P, Meikle S, et al. Altered left ventricular longitudinal diastolic function correlates with reduced systolic function immediately after anthracycline chemotherapy. Eur Heart ] Cardiovasc Imaging 2013;14:228-34.

66. Grothues F, Smith G, Moon JC, Bellenger N, Collins P, Klein H, et al. Comparison of interstudy reproducibility of cardiovascular magnetic resonance with two-dimensional echocardiography in normal subjects and in patients with heart failure or left ventricular hypertrophy. Am J Cardiol 2002;90:29-34.

67. Cerqueira M, Weissman N, Dilsizian V, Jacobs A, Kaul S, Laskey W, et al. American Heart Association Writing Group on Myocardial Segmentation and Registration for Cardiac Imaging: Standardized myocardial segmentation and nomenclature for tomographic imaging of the heart. A statement for healthcare professionals from the Cardiac Imaging Committee of the Council on Clinical Cardiology of the American Heart Association. Circulation 2002;105:539-42.

68. Caudron J, Fares J, Bauer F, Dacher JN. Evaluation of left ventricular diastolic function with cardiac MR imaging. Radiographics 2011;31: 239-59.

69. Korosoglou G, Futterer S, Humpert P, Riedle N, Lossnitzer D, Hoerig B, et al. Strain-encoded cardiac MR during high-dose dobutamine stress testing: comparison to cine imaging and to myocardial tagging. J Magn Reson Imaging 2009;29:1053-61.

70. Jung B, Mark1 M, Foll D, Hennig J. Investigating myocardial motion by MRI using tissue phase mapping. Eur J Cardiovasc Surg 2006; 29:S150-7.

71. Cury R, Nieman K, Shapiro M, Butler J, Nomura C, Ferencik M, et al. Comprehensive assessment of myocardial perfusion defects, regional wall motion, and left ventricular function by using 64-section multidetector CT. Radiology 2008;248:466-75.

72. Plumhans C, Muhlenbruch G, Rapaee A, Sim KH, Seyfarth T, Gunther R, et al. Assessment of global right ventricular function on 64-MDCT com pared with MRI. Am J Roentgenol 2008; 190:1358-61.

73. Adams M, Lipsitz S, Colan S, Tarbell N, Treves S, Diller L, et al. Cardiovascular status in long-term survivors of Hodgkin's disease treated with chest radiotherapy. J Clin Oncol 2004;22:3139-48.

74. Brouwer C, Postma A, Vonk J, Zwart N, van den Berg M, BinkBoelkens $\mathrm{M}$, et al. Systolic and diastolic dysfunction in long-term adult survivors of childhood cancer. Eur J Cancer 2011;47:2453-62.

75. Kupeli S, Hazirolan T, Varan A, Akata D, Alehan D, Hayran M, et al. Evaluation of coronary artery disease by computed tomography angiography in patients treated for childhood Hodgkin's lymphoma. J Clin Oncol 2010;28:1025-30.

76. Constine L, Schwartz R, Savage D, King V, Muhs A. Cardiac function, perfusion, and morbidity in irradiated long-term survivors of Hodgkin's disease. Int J Radiat Oncol Biol Phys 1997;39:897-906.

77. Messroghli D, Nordmeyer S, Dietrich T, Dirsch O, Kaschina E, Savvatis K, et al. Assessment of diffuse myocardial fibrosis in rats using small-animal Look-Locker inversion recovery T1 mapping. Circ Cardiovasc Imaging 2011;4:636-40.

78. Hering D, Faber L, Horstkotte D. Echocardiographic features of radiation-associated valvular disease. Am J Cardiol 2003;92:226-30.

79. Malanca M, Cimadevilla C, Brochet E, lung B, Vahanian A, MessikaZeitoun D. Radiotherapy-induced mitral stenosis: a three-dimensional perspective. J Am Soc Echocardiogr 2010;23:1080-2.

80. Forman M, Virmani R, Robertson R, Stone W. Mitral annular calcification in chronic renal failure. Chest 1984;85:367-71.

81. Fulkerson P, Beaver B, Auseon J, Graber H. Calcification of the mitral annulus: etiology, clinical associations, complications and therapy. Am I Med 1979;66:967-77.

82. Straumann E, Meyer B, Misteli M, Blumberg A, Jenzer H. Aortic and mitral valve disease in patients with end stage renal failure on long-term haemodialysis. Br Heart J 1992;67:236-9.

83. Cosyns B, Droogmans S, Rosenhek R, Lancellotti P. Drug-induced valvular heart disease. Heart 2013;99:7-12.

84. Baumgartner H, Hung J, Bermejo J, Chambers J, Evangelista A, Griffin B, et al., EAE/ASE. Echocardiographic assessment of valve stenosis: EAE/ASE recommendations for clinical practice. Eur J Echocardiogr 2009;10:1-25.

85. Lancellotti P, Tribouilloy C, Hagendorff A, Moura L, Popescu B, Agricola E, et al., European Association of Echocardiography. European Association of Echocardiography recommendations for the assessment of valvular regurgitation. Part 1: aortic and pulmonary regurgitation (native valve disease). Eur J Echocardiogr. 2010;11:223-44.

86. Lancellotti P, Moura L, Pierard L, Agricola E, Popescu B, Tribouilloy C, et al., European Association of Echocardiography. European Association of Echocardiography recommendations for the assessment of valvular regurgitation. Part 2: mitral and tricuspid regurgitation (native valve disease). Eur J Echocardiogr 2010;11:307-32.

87. Zoghbi W, Enriquez-Sarano M, Foster E, Grayburn P, Kraft C, Levine R, et al., American Society of Echocardiography. Recommendations for evaluation of the severity of native valvular regurgitation with twodimensional and Doppler echocardiography. J Am Soc Echocardiogr 2003; 16:777-802.

88. Machann W, Beer M, Breunig M, Angermann C, Seufert I, Schwab F, et al. Cardiac magnetic resonance imaging findings in 20-year survivors of mediastinal radiotherapy for Hodgkin's disease. Int J Radiat Oncol Biol Phys 2011;79:1117-23.

89. Abdulla J, Sivertsen J, Kofoed K, Alkadhi H, LaBounty T, Abildstrom S, et al. Evaluation of aortic valve stenosis by cardiac multislice computed tomography compared with echocardiography: a systematic review and meta-analysis. J Heart Valve Dis 2009;18:634-43.

90. Feuchtner G, Dichtl W, Muller S, Jodocy D, Schachner T, Klauser A, et al. 64-MDCT for diagnosis of aortic regurgitation in patients referred to CT coronary angiography. Am J Roentgenol 2008;191:1-7.

91. Van de Heyning C, Magne J, Vrints C, Pierard L, Lancellotti P. The role of multi-imaging modality in primary mitral regurgitation. Eur Heart J Cardiovasc Imaging 2012;13:139-51.

92. Sicari R, Nihoyannopoulos P, Evangelista A, Kasprzak J, Lancellotti P, Poldermans D, et al., European Association of Echocardiography. Stress echocardiography expert consensus statement: European Association of Echocardiography (EAE) (a registered branch of the ESC). Eur J Echocardiogr 2008;9:415-37.

93. Armstrong W, Pellikka P, Ryan T, Crouse L, Zoghbi W. Stress echocardiography: recommendations for performance and interpretation of stress echocardiography. Stress echocardiography task force of the nomenclature and standards committee of the American Society of Echocardiog raphy. J Am Soc Echocardiogr 1998;11:97-104. 
94. Heidenreich P, Schnittger I, Strauss H, Vagelos R, Lee B, Mariscal C, et al. Screening for coronary artery disease after mediastinal irradiation for Hodgkin's disease. J Clin Oncol 2007;25:43-9.

95. Achenbach S, Raggi P. Imaging of coronary atherosclerosis by computed tomography. Eur Heart J 2010;31:1442-8.

96. Nandalur K, Dwamena B, Choudhri A, Nandalur S, Reddy P, Carlos R. Diagnostic performance of positron emission tomography in the detection of coronary artery disease: a meta-analysis. Acad Radiol 2008; 15 : 444-51.

97. Greenwood J, Maredia N, Younger J, Brown J, Nixon J, Everett C, et al. Cardiovascular magnetic resonance and single-photon emission com puted tomography for diagnosis of coronary heart disease (CEMARC): a prospective trial. Lancet 2012;379:453-60.

98. Knez A, Becker A, Leber A, White C, Becker C, Reiser M, et al. Relation of coronary calcium scores by electron beam tomography to obstructive disease in 2,115 symptomatic patients. Am J Cardiol 2004;93:1150-2.

99. Nieman K, Galema T, Neefjes L, Weustink A, Musters P, Moelker A, et al. Comparison of the value of coronary calcium detection to computed tomographic angiography and exercise testing in patients with chest pain. Am J Cardiol 2009;104:1499-504.

100. Paech D, Weston Al. A systematic review of the clinical effectiveness of 64-slice or higher computed tomography angiography as an alternative to invasive coronary angiography in the investigation of suspected coronary artery disease. BMC Cardiovasc Disord 2011;11:32. http: //dx.doi.org/10.1186/1471-2261-11-32.

101. Rademaker J, Schoder H, Ariaratnam N, Strauss H, Yahalom J, Steingart R, et al. Coronary artery disease after radiation therapy for Hodgkin's lymphoma: coronary CT angiography findings and calcium scores in nine asymptomatic patients. Am J Roentgenol 2008;191:32-7.

102. Bamberg F, Becker A, Schwarz F, Marcus R, Greif M, von Ziegler F, et al. Detection of hemodynamically significant coronary artery stenosis: incremental diagnostic value of dynamic CT-based myocardial perfusion im aging. Radiology 2011;260:689-98.

103. Lardo A, Cordeiro M, Silva C, Amado L, George R, Saliaris A, et al. Contrast-enhanced multidetector computed tomography viability imaging after myocardial infarction: characterization of myocyte death, microvascular obstruction, and chronic scar. Circulation 2006;113:394-404.

104. Glanzmann C, Huguenin P, Lutolf U, Maire R, Jenni R, Gumppenberg V. Cardiac lesions after mediastinal irradiation for Hodgkin's disease. Radiother Oncol 1994;30:43-54.

105. Marks L, Yu X, Prosnitz R, Zhou SM, Hardenbergh P, Blazing M, et al. The incidence and functional consequences of RT-associated cardiac perfusion defects. Int J Radiat Oncol Biol Phys 2005;63:214-23.

106. Gayed I, Liu H, Yusuf S, Komaki R, Wei X, Wang X, et al. The prevalence of myocardial ischemia after concurrent chemoradiation therapy as detected by gated myocardial perfusion imaging in patients with esophageal cancer. J Nucl Med 2006;47:1756-62.

107. Gayed I, Gohar S, Liao Z, McAleer M, Bassett R, Yusuf S. The clinical im plications of myocardial perfusion abnormalities in patients with esophageal or lung cancer after chemoradiation therapy. Int I Cardiovasc Imaging 2009;25:487-95.

108. Maunoury C, Pierga J, Valette H, Tchernia G, Cosset J, Desgrez A. Myocardial perfusion damage after mediastinal irradiation for Hodgkin's dis- ease: a thallium-201 single photon emission tomography study. Eur I Nucl Med 1992;19:871-3

109. Pierga J, Maunoury C, Valette H, Socie G, Girinski T, Tchernia G, et al. Follow-up thallium-201 scintigraphy after mantle field radiotherapy for Hodgkin's disease. Int J Radiat Oncol Biol Phys 1993;25:871-6.

110. Plummer C, Henderson R, O'Sullivan J, Read S. Ischemic stroke and transient ischemic attack after head and neck radiotherapy: a review. Stroke 2011;42:2410-8.

111. Dymarkowski S, Bosmans H, Marchal G, Bogaert J. Three-dimensional MR angiography in the evaluation of thoracic outlet syndrome. Am J Roentgenol 1999;173:1005-8.

112. Veinot $E$, Edwards W. Pathology of radiation-induced heart disease: a surgical and autopsy study of 27 cases. Hum Pathol 1996;27:766-73.

113. Yeh E, Tong A, Lenihan D, Yusuf S, Swafford J, Champion C, et al. Cardiovascular complications of cancer therapy: diagnosis, pathogenesis, and management. Circulation 2004; 109:3122-31.

114. Heidenreich P, Hancock S, Lee B, Mariscal C, Schnittger I. Asymptomatic cardiac disease following mediastinal irradiation. J Am Coll Cardiol 2003; 42:743-9.

115. Lund M, Ihlen H, Voss B, Abrahamsen A, Nome O, Kongerud I, et al. Increased risk of heart valve regurgitation after mediastinal radiation for Hodgkin's disease: an echocardiographic study. Heart 1996; 75:591-5.

116. Hull M, Morris C, Pepine C, Mendenhall N. Valvular dysfunction and carotid, subclavian, and coronary artery disease in survivors of Hodgkin lymphoma treated with radiation therapy. JAMA 2003;290:2831-7.

117. Vahanian A, Alfieri O, Andreotti F, Antunes M, Baron-Esquivias G Baumgartner $\mathrm{H}$, et al., Joint Task Force on the Management of Valvular Heart Disease of the European Society of Cardiology (ESC), European Association for Cardio-Thoracic Surgery (EACTS). . Guidelines on the management of valvular heart disease (version 2012). Eur Heart J 2012; 33:2451-96.

118. Bonow R, Carabello B, Chatterjee K, Leon A Jr., Faxon D, Freed M, et al., American College of Cardiology/American Heart Association Task Force on Practice Guidelines. 2008 focused update incorporated into the ACC/AHA 2006 guidelines for the management of patients with valvular heart disease: a report of the American College of Cardiology/American Heart Association Task Force on Practice Guidelines (Writing Committee to revise the 1998 guidelines for the management of patients with valvular heart disease). Endorsed by the Society of Cardiovascular Anesthesiologists, Society for Cardiovascular Angiography and Interventions, and Society of Thoracic Surgeons. J Am Coll Cardiol 2008;52:142.

119. Orzan F, Brusca A, Conte M, Presbitero P, Figliomeni M. Severe coronary artery disease after radiation therapy of the chest and mediastinum: clinical presentation and treatment. Br Heart J 1993;69:496-500.

120. Gansera B, Schmidtler F, Angelis I, Botzenhardt F, Schuster T, Kiask T, et al. Quality of internal thoracic artery grafts after mediastinal irradiation. Ann Thorac Surg 2007;84:1479-84.

121. Schwartz RG, McKenzie WB, Alexander J, Sager P, D'Souza A, Manatunga A, et al. Congestive heart failure and left ventricular dysfunction complicating doxorubicin therapy: a seven year experience using serial radionuclide angiocardiography. Am J Med 1987;82:1109-18. 